\title{
Investigation of Properties and Performance of Ceramic Composite Components: Final Report on Phase II
}

\author{
October 31, 1994 \\ Research sponsored by the U.S. Department of Energy, \\ Fossil Energy \\ Advanced Research and Technology Development Program \\ Report Prepared by \\ W. A. Curtin, K. L. Reifsnider, L. L. S. Oleksuk and W. W. Stinchcomb* \\ Materials Response Group \\ Virginia Polytechnic Institute and State University \\ Blacksburg, VA 24061 \\ under \\ Subcontract Number 19X-SA946C
}

for

OAK RIDGE NATIONAL LABORATORY

Oak Ridge, Tenessee 37831

managed by

MARTIN MARIETTA ENERGY SYSTEMS, INC.

for the

U.S. Department of Energy

under Contract No. DE-AC05-84OR21400

DISCLAIMER

$(*)$ deceased

\begin{abstract}
This report was prepared as an account of work sponsored by an agency of the United States Government. Neither the United States Government nor any agency thereof, nor any of their employees, makes any warranty, express or implied, or assumes any legal liability or responsibility for the accuracy, completeness, or usefulness of any information, apparatus, product, or process disclosed, or represents that its use would not infringe privately owned rights. Reference herein to any specific commercial product, process, or service by trade name, trademark, manufacturer, or otherwise does not necessarily constitute or imply its endorsement, recommendation, or favoring by the United States Government or any agency thereof. The views and opinions of authors expressed herein do not necessarily state or reflect those of the United States Government or any agency thereof.
\end{abstract}




\section{DISCLAIMER}

Portions of this document may be illegible in electronic image products. Images are produced from the best available original document. 


\section{Table of Contents}

I. Introduction 2

II. Phase II Accomplishments 5

1. SiC/SiC Tubular Components 5

2. Investigation of Nicalon/CAS Flat Specimen 19

3. Performance Simulation - The MRLife Code 26

III. Summary 33

IV. References $\quad 35$

V. Students supported by contract $\quad 37$

VI. Papers Published under contract 37

$\begin{array}{ll}\text { VII. Distribution List } & 38\end{array}$ 


\section{Introduction*}

The objective of the Fossil Energy Advanced Research and Technology Development (AR \& TD) Materials Program is to conduct research and development on materials for longer-term fossil energy applications as well as for generic needs of various fossil fuel technologies. These needs have prompted research aimed toward a better understanding of material behavior in fossil energy environments and the development of new materials capable of substantial enhancement of plant operations and reliability.

The Materials Response Group (MRG) program addresses the need for reliable and durable structural ceramic composites to perform in high temperature environments. The research effort provides an experimental and analytical basis for the transition from properties to performance. The program is a pioneering effort to make a first step beyond the limited characterization of small samples and coupons to a comprehensive characterization of the mechanical performance of complex engineering components such as ceramic composite tubes subjected to static and cyclic multi-axial loading and elevated temperature over various time periods. Characterization of the mechanical performance of ceramic composite components includes both experimental observations and measurements of long-term behavior and predictions of remaining strength and life under realistic service environments.

Phase I of this program involved the integration of analytical and experimental capabilities of the MRG to support the development of the MRLife code for the prediction of remaining strength and life of ceramic composite components at elevated temperatures. These goals were accomplished and with notable success. Phase I results are presented and described in Reference 1 and include:

- design, construction, installation, and acceptance testing of an Instron computer controlled, high stiffness biaxial test facility with hydraulic grips, high temperature $\left(1500^{\circ} \mathrm{C}\right)$ furnace, and extensometer,

- design, fabrication, and evaluation of chopped graphite fiber (Hercules HMU-PVA-3k)/borosilicate glass matrix (CorningCGW-7070) composite tubes,

- investigation and application of nondestructive test methods to monitor the damage development process,[2]

* Research sponsored by the U.S. Department of Energy, Fossil Energy Advanced Research and Technology Development Materials Program, DOE/FE AA 151010 0, Work Breakdown Structure element VPI-1. 
- completion of a data set for room temperature, monotonic and cyclic axial loading of graphite fiber/borosilicate glass matrix tubes,

- development of a high temperature damage model based on the critical element concept,

- development and validation of a life prediction model (MRLife) for ceramic composites.

The purpose of Phase II of the Investigation of Properties and Performance of Ceramic Composite Components has been to build on and extend the work completed during Phase I to further advance the transition from properties of ceramic composite materials to performance of ceramic composite components used in fossil energy environments. The work in Phase II has utilized two unique capabilities developed during Phase I of the program:

- a high temperature, multiaxial mechanical test facility, and

- a mechanistic, performance simulation code (MRLife) which brings together the research results in a predictive model for the performance of ceramic composite components.

The specific tasks of Phase II were:

- Develop and validate reliable and accurate high temperature, biaxial mechanical test methods for structural ceramic composite components. (Section II.1)

- Test and evaluate ceramic composite components, specifically tubes. (Section II.1)

- Characterize long-term, mechanical performance of ceramic composite tubes at high temperatures. (Sections II.1, II.2)

- Develop a fundamental understanding of the mechanical degradation and performance limitations of ceramic composite components under service conditions. (Section II.2)

- Develop predictive models for damage tolerance and reliability. (Section II.3)

- $\quad$ Relate component performance to microstructure and, thereby, provide feedback to the associated process-development effort, under D. P. Stinton at ORNL, to improve performance. (Section II.1) 
where the sections of this report which discuss the accomplishments against each task have been noted in parenthesis.

To accomplish the above goals, Phase II was conducted according to a systematically designed and carefully coordinated series of investigations consisting of laboratory tests, model development, and validations to describe, measure, and reliably predict the long term, high temperature performance of ceramic composites subjected to biaxial mechanical loading.

The first step in the approach has been the establishment of nondestructive evaluation (NDE) methods that are most sensitive and suitable for the examination of the material systems under test, for the conditions of interest. The damage and failure modes influence these choices.

The second step in the approach is the application of monotonic and cyclic loading (for "long-term" testing). The number of cycles or time which defines "long-term" depends on the expected service requirements of the components associated with the materials under test. However, in general, up to about 100,000 cycles of loading and time periods of up to about 36 hours (at temperature) were used for the present program, with loading at room and elevated temperature. The focus is on the determination of the damage and failure modes, and the relationship between microstructure and performance under both monotonic and cyclic loading. This has been accomplished with sequential, interrupted mechanical testing and examination of the specimens with appropriate NDE methods as determined in step one.

The third step in the approach has been the modeling of those damage and failure modes using mechanics analysis. The experience of the Materials Response Group has been used for this effort. Models of fiber-controlled and matrix-controlled failure in tension, compression, and shear were modified as needed for this task, and used as the basis for the modeling of long term behavior.

The final step in the approach involves more complex combinations of thermal and mechanical loading, with particular attention to creep-fatigue interactions. The basic models of strength will be combined into a mechanistic performance simulation model which will predict remaining strength and life as a function of loading history. This collective model is actually a continuation and refinement of a modeling activity by the Materials Response Group that has produced a code series called MRLife (now in its ninth release).

The details of the specific accomplishments in Phase II are discussed below in Section II, and are divided into three related parts:

1. Investigation of $\mathrm{SiC} / \mathrm{SiC}$ tube components manufactured at Oak Ridge National Laboratory, 
2. Investigation of SiC/CAS flat samples, which provide additional extensive data on failure modes at room and elevated temperatures, and under cyclic loading,

3. Development and validation of MRLife, as applied to both tube and flat specimens.

As of the close of Phase II, considerable insight into fatigue damage modes in model $\mathrm{CMC}$ systems has been gained through the studies of SiC/CAS materials. This has driven the further developments of the MRLife Performance Simulation code. The investigation into $\mathrm{SiC} / \mathrm{SiC}$ tube components has identified various processing microstructure/performance correlations, and possible elevated temperature degradation. We are currently working to extend such correlations to understanding long-term, high temperature damage modes, and to relate damage mechanisms observed in flat specimens to those in tube components. The MRLife code is also now in a position to investigate performance of $\mathrm{SiC} / \mathrm{SiC}$ composites.

The planned Phase III effort will utilize the strong base of equipment capability, damage mode discoveries, microstructure dependencies, and analytic model development, delivered under Phases I and II to further develop a data-base and understanding of ceramic tube components. Currently, the MRG has five third and fourth generation $\mathrm{CVI} \mathrm{SiC/SiC} \mathrm{tubes} \mathrm{recently} \mathrm{provided} \mathrm{by} \mathrm{ORNL} \mathrm{which} \mathrm{will} \mathrm{be} \mathrm{tested}$ and evaluated at both low and high temperatures. The spectrum of approaches used in Phase III will be those utilized in Phase II on both components and flat specimens. The results obtained will be used to guide further process development, to provide baseline data for engineering designs with these particular components, and to validate and extend the performance simulation code so as to predict durability in specific fossil energy applications.

\section{Phase II Accomplishments}

\section{II.1 SiC/SiC Tubular Components}

In this subsection, we describe the work and accomplishments in the area of ceramic component performance and microstructure/property relationships.

\section{II.1.a. Specimens and Processing}

The tubular specimens had a $2.5 \mathrm{~cm}$. ID, $0.6 \mathrm{~cm}$. wall thickness, and a $20 \mathrm{~cm}$. length. Nicalon, a SiC-based polymer-derived fiber that is microcrystalline/amorphous in nature and contains significant amounts of silica, was utilized for the fabrication of all preforms.[3-5] Filament winding was used to simulate components such as combustors or headers that require high hoop or radial strengths but relatively modest axial strengths. Three dimensional braiding was used to simulate applications such as burner tubes or heat exchangers that require high axial strengths but only modest hoop strengths. Cloth 
wrapping was utilized to simulate components that require comparable strengths in both the hoop and axial directions.

Preforms were filament wound onto graphite mandrels at the U.S. Department of Energy K-25 Plant at the Oak Ridge National Laboratory. Fibers were wound $10^{\circ}$ off the hoop direction to insure adequate axial strength. Adjacent fiber tows were placed in contact with each other to prevent the formation of large pores during the winding of subsequent layers. This winding procedure produced a preform with a fiber loading of $\approx$ 40 vol\% and fine porosity distributed throughout the preform. Quadrax Corporation prepared 3D braided preforms on graphite mandrels for this study. Because thorough infiltration of braided preforms with low fiber contents (15 - 30 vol\%) had proven to be very difficult, special procedures were developed to braid tubular preforms that contained $\approx 38$ vol\% Nicalon fibers. Cloth-wrapped preforms were prepared at the Oak Ridge National Laboratory with fiber contents of $\approx 32$ vol\%.

Forced chemical vapor infiltration as developed at the Oak Ridge National Laboratory utilizes a thermal gradient and a pressure gradient to efficiently infiltrate flat

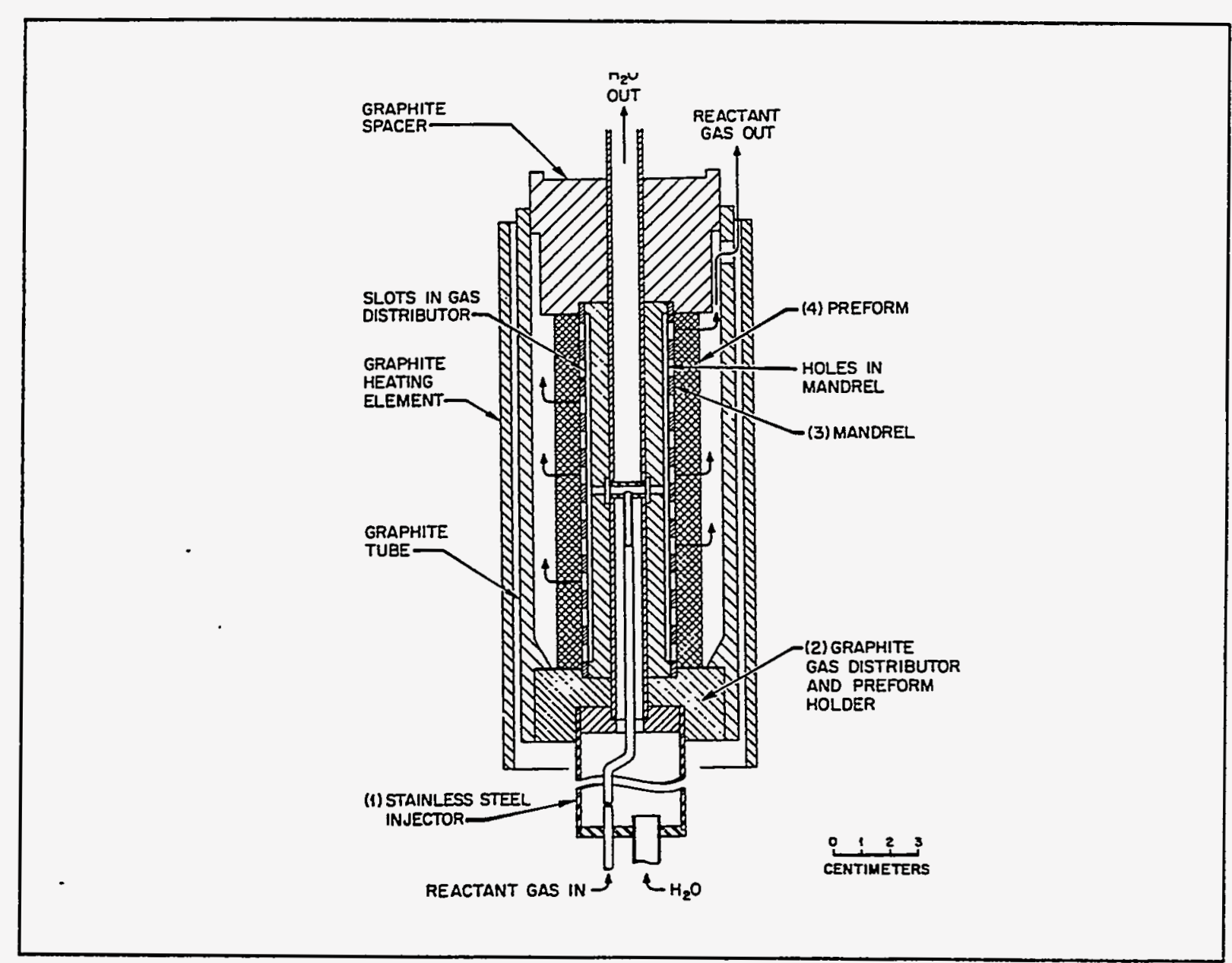

Figure 1. Schematic of the Forced CVI system used to infiltrate tube components 
plate preforms of thick cross-section. [3,4] Tubular preforms can be infiltrated by creating a thermal gradient from the outside of the tube to the inside.[5] While the outside of the preform is heated, cold water is circulated through the stainless steel injector to cool the inside diameter of the fibrous preform (Fig. 1). The gaseous reactants enter the furnace through tubing that runs within the water cooling passage. Reactants flow from the tubing in the cooling passage into a graphite gas distributor and are dispersed along the length of the preform through parallel slots in a graphite gas distributor. Reactants then proceed uniformly through holes in the graphite mandrel into the preform.

Densification of the tubular preforms with $\mathrm{SiC}$ can be accomplished using hydrogen and methyltrichlorosilane $\left(\mathrm{CH}_{3} \mathrm{SiCl}_{3}\right.$ or MTS). Decomposition of the MTS and deposition of $\mathrm{SiC}$ occurs as the gases approach the higher temperature regions near the outer diameter of the perform. Deposition of $\mathrm{SiC}$ within the hot region of the preform increases the density and thermal conductivity of the material. Therefore, the deposition zone moves from the outer diameter, hotter regions toward the inner diameter, cooler regions as their temperature increases.

Preforms of each fiber architecture were effectively infiltrated using this system. The high fiber content of the filament wound preforms produced sufficient backpressures within the preform to disperse the reactants along the length of the tube. The hottest regions of the preform densified first, which forced reactants into less dense areas of the preform. The lower fiber content of the braided preforms produced less efficient infiltration. The porosity created by the braid was uniformly distributed; however, because of aligned porosity, the permeability was relatively high and reactants moved through the preform without depositing SiC. The cloth wrapped preforms exhibited efficient infiltration despite the low fiber contents. The permeability of the preforms was apparently less than the braided preforms permitting the reactants to efficiently contact the fiber surfaces and deposit the matrix material.

Before summarizing any of the experimental work performed on the Oak Ridge tubes, a description of the tubes and explanation of the nomenclature is necessary. The tubes have been received in four batches. The tubes are labeled with a code that indicates in which batch the tube was received, for example, OR1 indicates that a tube was received in the first batch. Another code following that denotes exactly which tube from the batch is being discussed. That code also indicates the fiber architecture. The three possible fiber architectures are filament wound (F), braided (B) and cloth-wrapped (C). The cloth used is a $0^{\circ} / 90^{\circ}$ plain weave. Thus, OR1-B1 denotes that the tube was received in the first batch, is braided, and is the first braided tube in that batch. The third and final code indicates whether or not the tube has been treated for resistance to oxidation at elevated temperatures. Thus, a typical tube from the third batch is OR3-C1$\mathrm{HT}$, which is the first cloth-wrapped tube in the third batch, and is coated. The tubes in OR3 are all coated with 50 microns of $\mathrm{SiC}$. The following tubes have been received: 


\begin{tabular}{|l|l|l|l|}
\hline OR1 - F1 & OR2 - C1 & OR3 - C1 - HT & OR4 - C1 \\
\hline OR1 - C1 & OR2 - C2 & OR3 - C2 - HT & OR4 - C2 \\
\hline OR1 - B1 & OR2 - B1 & OR3 - C3 - HT & \\
\hline
\end{tabular}

This nomenclature is simple and easily expanded, but may pose some confusion if one reviews earlier reports. The first batch of tubes was initially labeled simply as OR1, OR2 and OR3 which in the new notation correspond to OR1-F1, OR1-C1 and OR1-B1 respectively. The expanded nomenclature is preferred because it is much more descriptive, and it will be used exclusively hereafter.

\section{II.1.b. Testing Procedures and Gripping}

The large diameter $\mathrm{SiC} / \mathrm{SiC}$ tube components have been mechanically tested using the Instron computer controlled, high stiffness biaxial test facility developed in Phase I of the program. This machine is capable of exerting 10 kips axial load and 5 kipinches of torsional load simultaneously, with special grips designed for tubes and an oven for elevated temperature experiments. An important effort involved the design of gripping methods for these components, and the use of tapered graphite end plugs to prevent both outright crushing of the tubes and failure from stress concentrations at the plug/tube corner. The configuration of gripping in the test facility is shown in Figure 2.

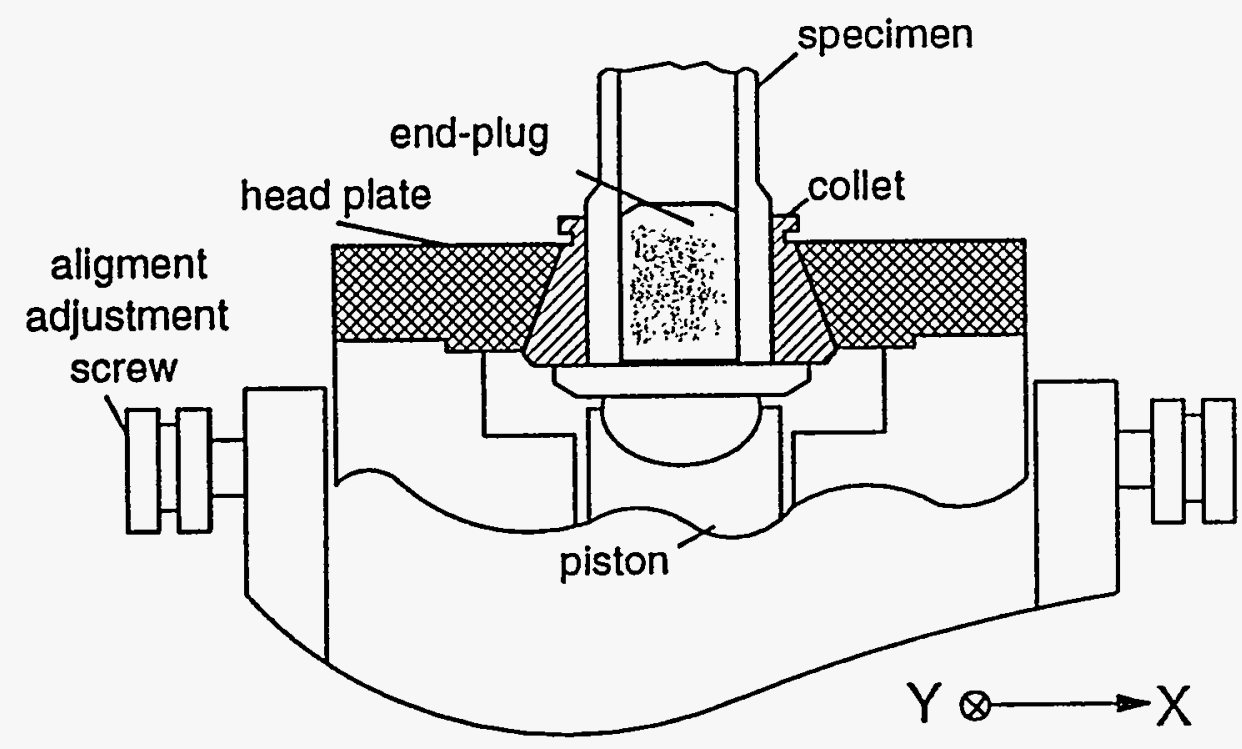

Figure 2. Schematic of the gripping system for large diameter tubes 


\section{II.1.c. Results on Generation 1 Tubes}

A number of different techniques have been used on the OR1 tubes to characterize completely the morphology and material properties. Radiography was initially used to identify any large defects prior to mechanical testing. The OR1 tubes were $\mathrm{x}$-rayed using a special apparatus shown in Figure 3 prior to any mechanical testing. The tubes were manually rotated so that 4 separate radiographs spanned the complete circumference of the tube and appear on the same film nearly continuously. As evident in Figure 4, which shows results for OR1-B1, the quality of the radiographs is generally

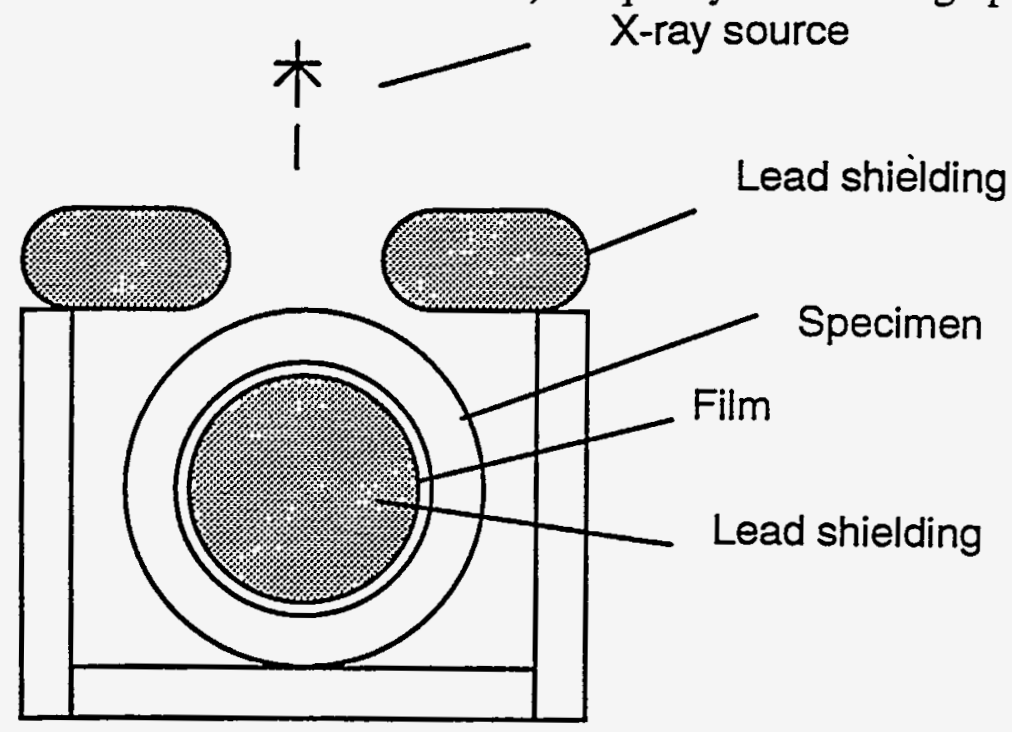

Figure 3. X-ray apparatus for tubes (side view)

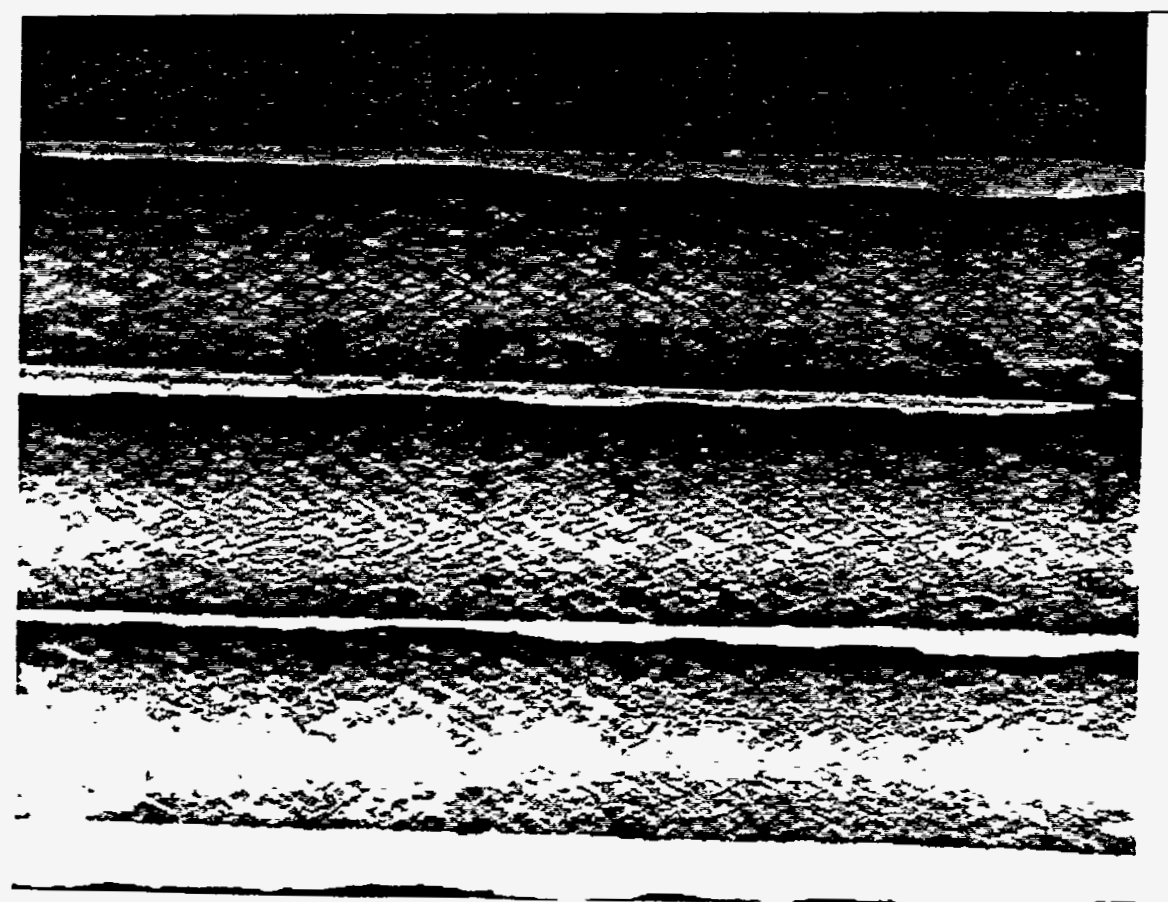

Figure 4. Radiograph of OR1-B1 
good and the fiber architecture is clearly visible. No large defects or regions of extremely low density (which would appear dark on the film) were found for any of the tubes. The only other density variations apparent in the radiographs are bright (higher density) regions which exhibit a regular pattern. These variations correspond to pattern of the discrete holes in the mandrel, indicating preferential reactant deposition around the holes. After OR1-F1 was tested to failure, radiographs of the two pieces were taken. Again, the radiographs were apparently of good quality, and the fiber architecture and variations in density due to mandrel holes were visible. However, there were no apparent signs of damage at the broken ends of the tube. Since there is damage at the failed ends visible both to the naked eye and under the electron microscope, the sensitivity of radiography appears limited to the detection of the most large scale variations and defects.

Ultrasonic C-scanning was briefly considered as a pre-test evaluation technique. Equipment to position and rotate the tubes for continuous circumferential scans was available and potentially adaptable to these tubes. However, because of the need for complete immersion in water and the difficulty of fully immersing the highly porous $\mathrm{CVI}$, this technique is not practical. C-scans of other laminated woven-cloth SiC-SiC specimens from another source were found to be unreadable, presumably due to very incomplete infiltration.

Tensile stress-strain data for tubes subjected to axial loading to approximately 20 $\mathrm{MPa}$ have been recorded using a high temperature extensometer to measure axial strains. Examples of those data are shown in Fig. 5 for the cloth-wrapped tube OR1-C1. The


Figure 5. Tensile stress-strain data for tube OR1-C1 at four temperatures 
specimens were also subjected to torsional loading, and data were taken with strain gages affixed to the specimens. These tests were successful, with no difficulties in specimen slippage or multiaxial load application. Data from tests on cloth-wrapped and braided tubes are shown in Fig. 6 . Fig. $6 a$ and $6 \mathrm{~b}$ show that the reproducibility of the test



Figure 6. Torsional loading data of $(\mathrm{a}, \mathrm{b})$ tube OR1-C1, (c) OR1-B1 
method is excellent. The strain gage data were also compared to extensometer readings for axial loading, as a consistency check. The results compared to within about 10 percent, in general. The shear stiffness of the braided tube $(127 \mathrm{GPa})$ was about 30 percent greater than that of the cloth wrapped tube (94 Gpa). Since the (fully dense) matrix is approximately twice the stiffness of the fibers, this is a reasonable and expected result.

Axial stiffness measurements were performed on the three OR 1 tubes at both ambient and elevated temperatures using the Instron high temperature extensometer. Room temperature stiffness was approximately $E \cong 22$ Msi for the filament wound $F 1$ tube, and 33.2 Msi for the cloth-wrapped C1 tube. Axial stiffness and shear modulus of OR1-C1 at room temperature were also measured using strain gages and are $E \cong 37.4$ Msi and $G \cong 13.7 \mathrm{Msi}$. The discrepancy between extensometer and strain gage measurements may be associated with point-to-point variations in stiffness as observed in Generation 2 tubes and described below. Axial stiffness and shear modulus of OR1-B1 at room temperature (using strain gages) and are $\mathrm{E} \cong 38.7 \mathrm{Msi}$ and $\mathrm{G} \cong 18.5 \mathrm{Msi}$.

Figure 7 shows the normalized axial stiffness variations with temperature for the three OR1 tubes tested in tension at temperatures up to $800^{\circ} \mathrm{C}$. The approximate time of exposure at elevated temperatures for OR1-F1 was 1.5 hours at $400^{\circ} \mathrm{C}, 2$ hours at $600^{\circ} \mathrm{C}$ and 0.5 hours at $800^{\circ} \mathrm{C}$, which is typical for all the tubes. It can be seen that a stiffness drop of $15 \%$ was observed for OR1-B1, and a 36\% drop was observed for both OR1-F1 and OR1-C1 (not shown). Stiffness changes in Nicalon fibers at temperatures up to $800^{\circ}$ $\mathrm{C}$ are generally quite small, although significant variations (of the order of magnitude we observed) at temperatures of the order of $1000^{\circ} \mathrm{C}$ have been reported.[6] Drops in stiffness of the fibers have been shown to be sensitive to the time of exposure and

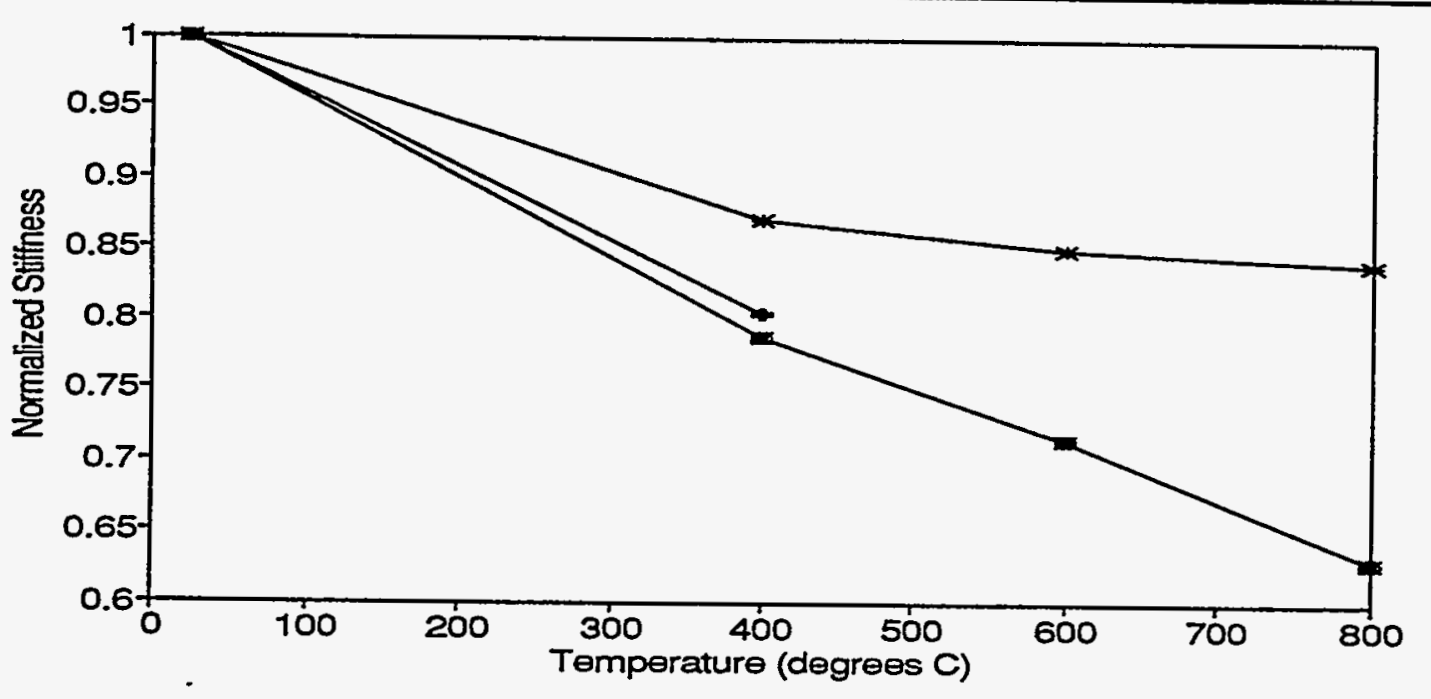

filament wound $\rightarrow$ cloth-wrapped $\rightarrow$ braided

Figure 7. Axial stiffness versus temperature for the three tube architectures 
reactive nature of the surrounding atmosphere.[6] Strength reductions for SiC-based fibers at $800^{\circ} \mathrm{C}$ have also been reported.[7] These reported reductions of the order of 15 percent were smaller than those which we have measured on the filament wound and cloth wrapped specimens, however.

Figure 8 shows the results of a repeated test on the cloth wrapped tube, in which the temperature was increased only to $600^{\circ} \mathrm{C}$. Notice that the room temperature measurements were repeated after the specimen cooled, showing that the variations in stiffness are not permanent. These stiffness changes are smaller than those obtained during the first test of that tube, shown in Fig. 7. We believe that some of the variation first observed were caused by hot air currents biasing the capacitance extensometer readings. We now make a special effort to protect the extensometer from such disturbances during elevated-temperature testing.



Figure 8. Repeated test of cloth-wrapped tube OR1-C1 up to $600 \mathrm{C}$.

It is doubtful that reductions in fiber stiffness totally account for the reductions in composite stiffness observed in our tests. In fact, the literature suggests that when 3-D fiber architectures are used, composite stiffness (and strength) reduction at temperatures up to about $1200^{\circ} \mathrm{C}$ are of the order of only about 15 percent.[8] It is more likely that the matrix material, and, especially, the carbon interface between the matrix and the fiber is degrading and contributing significantly to stiffness (and, in some cases, strength) loss.

In an effort to further identify the nature of some of the above mechanical measurements, sections were made by the/Oak Ridge National Laboratory and subjected to scanning electron microscopy at Virginia Tech. The OR1-F1 tube was investigated 
destructively after failing at 2900 pounds at $600^{\circ} \mathrm{C}$ on the second test. Figure 9 shows the arrangement of those sections. Figure 10 shows three micrographs, one from each of

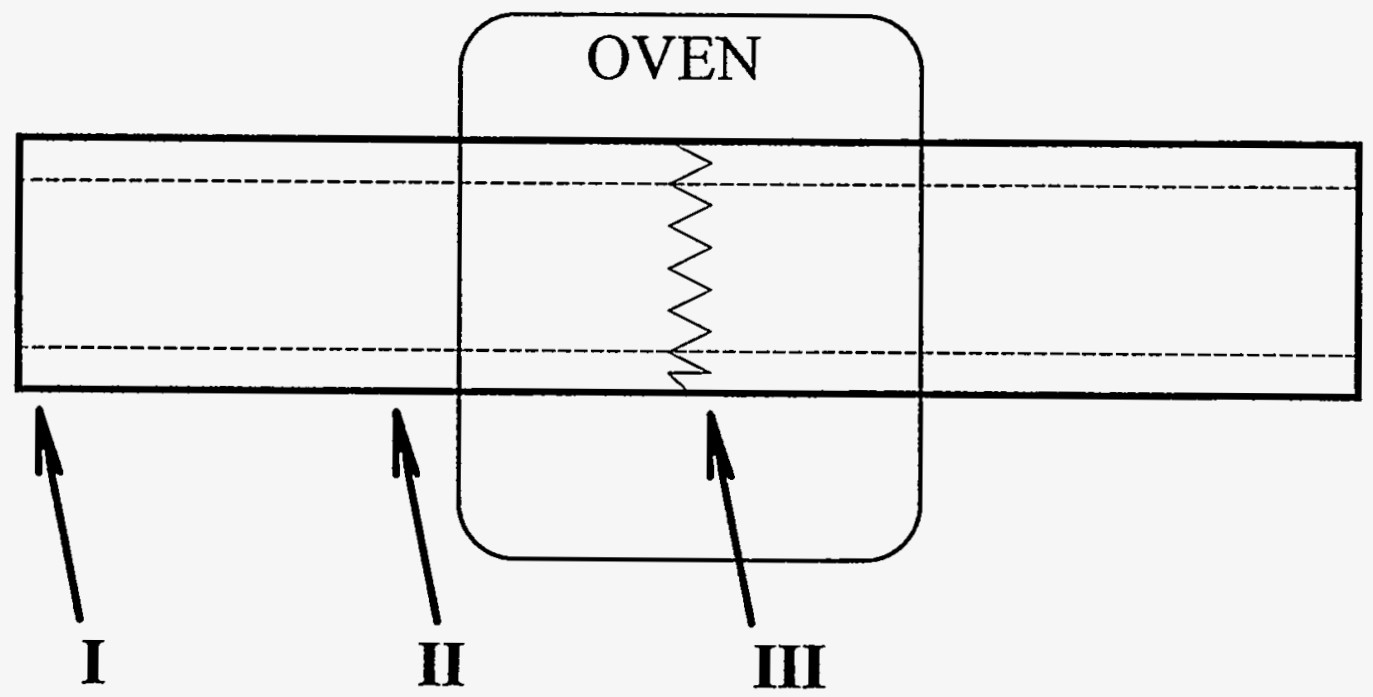

Figure 9. Locations of sections taken for SEM studies of filament wound tube. Sections I and II were outside the furnace.

regions I, II and III. These micrographs show no clear evidence of temperature-related damage. In region III there is some evidence of the loss of the carbon layer around the fibers, and some of the matrix cracks are seen to travel through the fibers rather than being diverted, suggesting that the bonding between the fibers and matrix has been increased by heat treatment. However, no substantial buildup of silicon oxide is seen in the micrographs. The striking contrast between the micrographs of Figure 10 does, however, reveal the drastically different microstructures along the length of the tube. Region III was relatively well-densified, Region I was moderately dense, but Region II was almost devoid of matrix material. Figure 10 is typical of the observed variations, and have motivated the more detailed study of microstructure/property relationships on Generation 2 tubes, as described below. These variations in microstructure for the OR1F1 tubes may occur in the other tubes, and account for the wide differences in modulus found between extensometer and strain gage measurements.

\section{II.1.d Results on Generation 2 Tubes}

Prior to extensive mechanical testing of the OR2 tubes, the tubes were first tested for the possible application of internal pressure, as an additional means of producing complex stress states beyond combined axial and torsional loading. The porosity observed in the OR1-F1 tube, and the difficulty with C-scanning, suggested that the tubes may be unable to hold pressurized gas. In order to verify this, a low-pressure pressurization fixture was built. Argon, externally supplied from a pressurized canister, was released into a tube and the pressure at the other end measured with a gauge. Tubes 

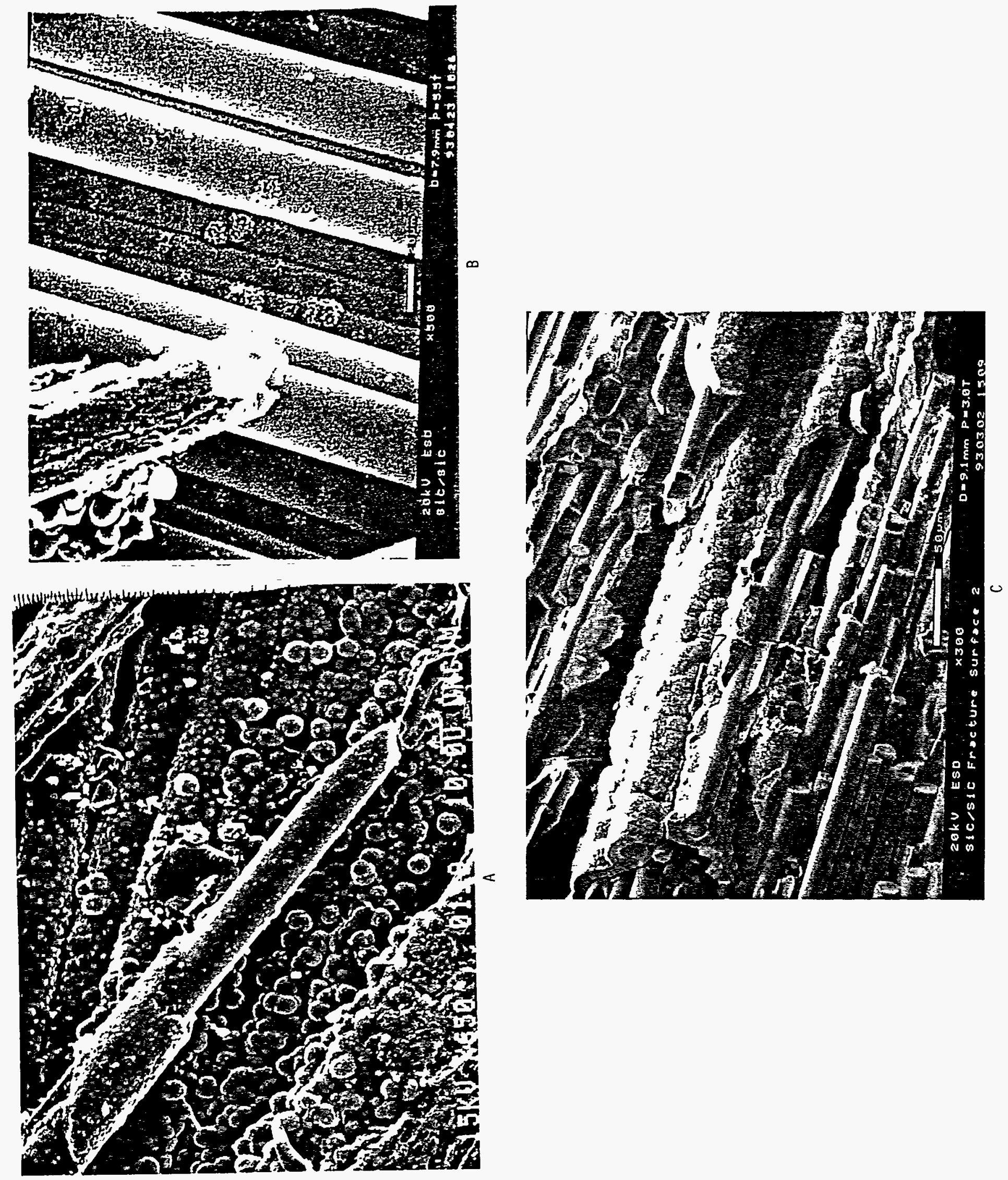

Figure 10. Micrographs from Regions I, II and III of the filament-wound tube OR1-F1. 
OR2-C1 and OR2-B1 were tested in the low-pressure fixture prior to any other tests; in other words, in an as-received condition. They were unable to sustain pressures below 5 psi. Similar subsequent experiments demonstrated that neither OR1-C1 and OR1-B1 could sustain even small pressure. Methods of inducing internal pressure during mechanical testing that do not rely on the tubes' ability to contain pressurized gas have been discussed, such as using bladders capable of withstanding elevated temperatures, but no further studies along these lines have been made to date.

Tube OR2-C2 has been equiped with experimental high temperature strain gages designed and attached by the Instrumentation Division of NASA Langley Research Center. Because the method of attaching these gages to $\mathrm{SiC} / \mathrm{SiC}$ is still in development, internal pressurization of this tube, no matter how slight, was not advised. These gages will theoretically operate up to $1500^{\circ} \mathrm{F}$ with much higher accuracy than is currently available. The gages have been found to operate perfectly at room temperature with excellent linearity, but our attempts to balance the gages at elevated temperatures have proven unsuccessful. The prospect of accurate high-temperature strain gauges is sufficiently alluring so as to motivate additional efforts on this system.

Mechanical tests at room temperature on the cloth-wrapped tube OR2-C1 have been performed. Because of a wide discrepancy in densification and morphology found in the Generation I tubes from point to point, tube OR2-C1 was outfitted with strain gages at one inch intervals along the length of the tube for five inches both front and back to specifically measure variations in local strain, and hence in local stiffness. The results of very small strain tests are shown in Figure 11. The axial stiffness was found to be approximately $20 \%$ higher on one end of the tube then elsewhere along the tube length, with smaller point-to-point variations at the other four locations. No apparent angular dependence of stiffness was found, the deformations on the front and back strain gages were essentially the same aside from possible small, opposing deflections associated with slight tube bending. The stiffness values measured everywhere except at the high stiffness end are rather lower than typical for flat specimens of this material system.

Under slightly larger axial tension of $3 \mathrm{ksi}$, a failure in the gripping system (not the sample) led to crushing of the tube OR2-C1. Destructive evaluation by scanning electron microscopy was then employed to assess the microstructural variations in this tube. Specimens were prepared from the sections of the tube corresponding to the locations of strain gages 1 and 5; that is, at either end of the tube where the stiffness values were highest and lowest, respectively. Scanning electron microscopy revealed significant variation of morphology at positions 1 and 5 . Figure 12a shows a typical view at position 1 , where the modulus was highest. The matrix has a regularly pebbled surface, and the fiber/matrix structures tend to "wrap around" surrounding fiber/matrix structures, indicating good mechanical contact between orthogonal fiber tows at this location. Figure $12 \mathrm{~b}$ shows a typical view at position 5 , where the modulus was lowest. Here the matrix has an uneven surface of irregularly sized features and, moreover, the orthogonal fiber tows have little or no contact. 


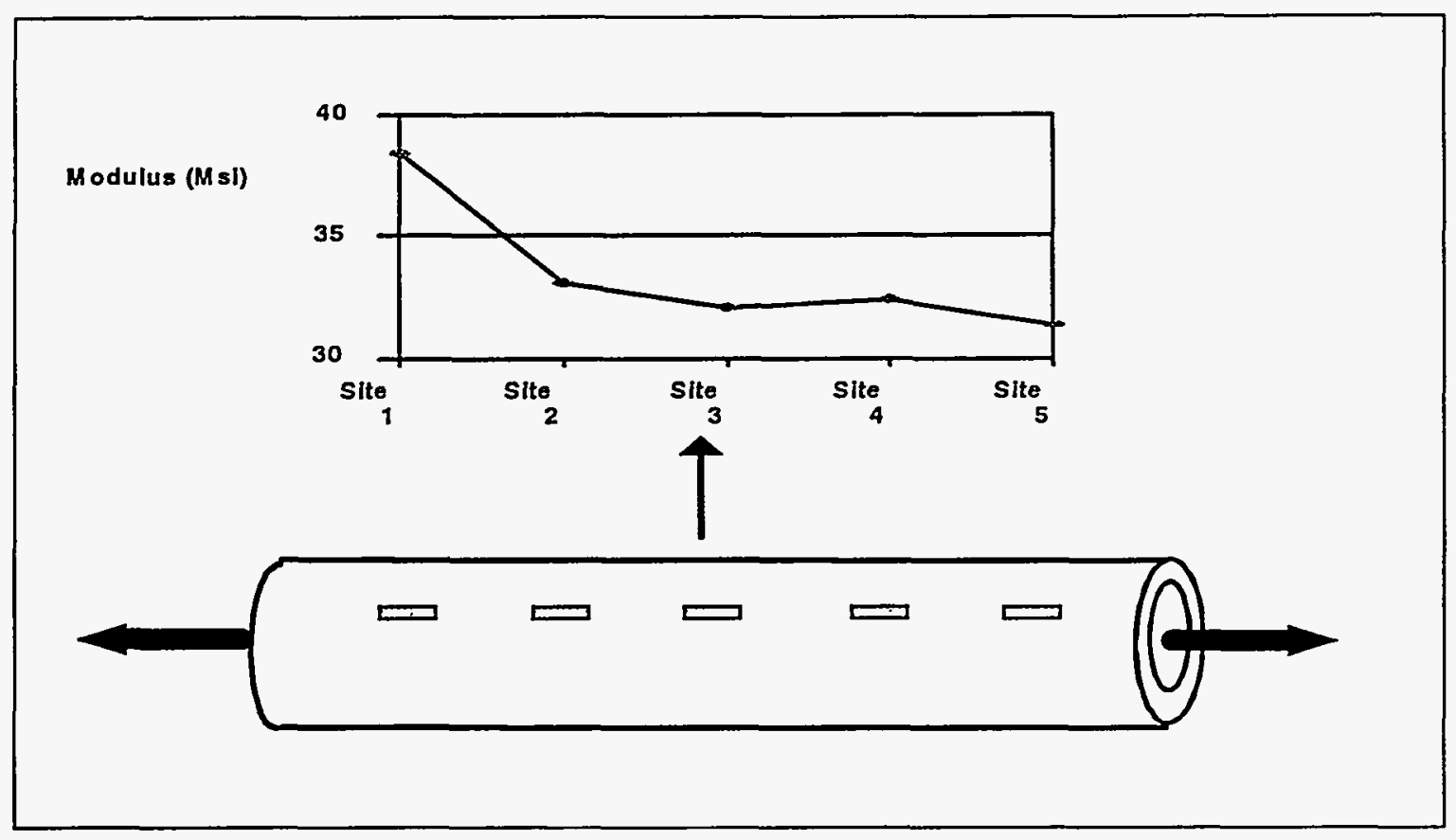

Figure 11. Variation of axial stiffness along length of tube OR2-C1

The above variations in microstructure are very consistent with the variations found in the local modulus. In particular, while the fibers and matrix in the axial tows are expected to contribute a roughly rule-of-mixtures value to the axial stiffness, the contribution to axial stiffness from the transverse tows is highly dependent on both the connectivity within the transverse tow and the connectivity of that tow to the neighboring axial tows. Moderate variations in density can thus lead to larger-than-expected axial stiffness variations. We are presently developing a model to predict the axial stiffness of cross-ply CVI materials as a function of density. Additional data from other Oak Ridge programs on these materials has indicated a similar sensistivity of axial modulus to density, and will be utilized to verify the model. The correlations drawn from that data as applied to our current measurments of axial stiffness suggest that the high modulus region of the OR2-C1 tube has a density in the vicinity of $90 \%$ or higher, while the low modulus region has a density in the vicinity of only $85 \%$.

A potential explanation for the modulus variations along the tube length, and apparent density variations, is as follows. During Forced CVI processing, the tubes are sitting on a steel plate, with a small graphite preform holder, which is typically a heat sink. Thus, it is possible that there is a temperature gradient along the length of the tube, and that the dependence of densification rate on local temperature leads to processing variations with a bias toward the bottom of the tube. Future processing of tubes at Oak Ridge National Laboratory will thus be carried out with a recognition of the tube "top" and "bottom" to verify the present hypothesis. Modifications to the present processing system are also being considered to eliminate this potential source of axial temperature gradient. 

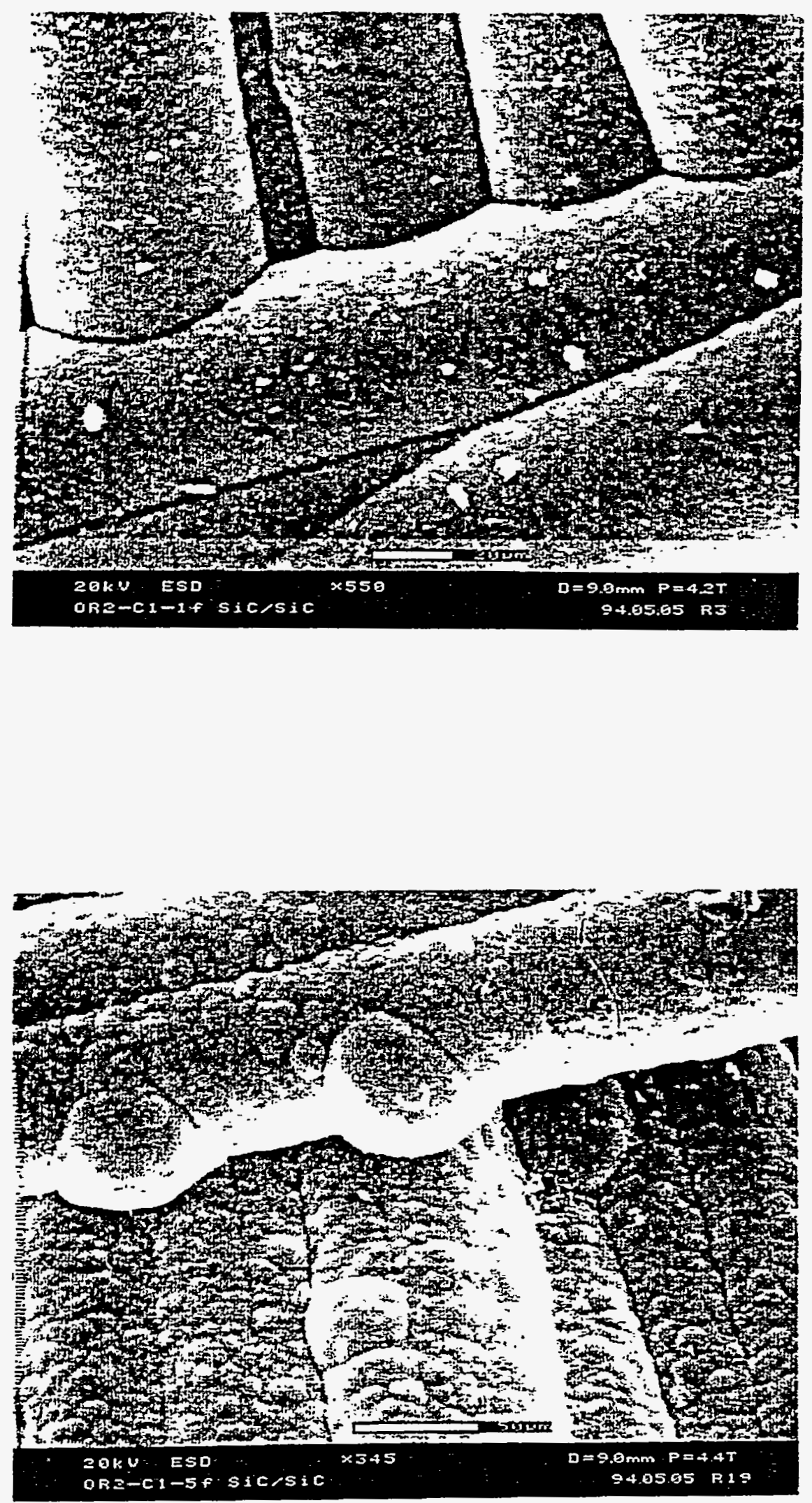

Figure 12. (a) typical view around position 1, (b) typical view around position 5 
Mechanical testing of Generation 3 tubes will investigate further the relationship between processing and mechanical performance. In particular, local stiffness variations at room temperature will be investigated as for the Generation 2 tubes. Then, tubes will be tested to failure under tension to determine a possible correlation of failure with local microstructure and stiffness. The failed tube will then be destructively sectioned and subject to two further studies. First, electron microscopy of polished cross-sections will be performed. Second, strength tests of the sectioned specimens will be performed to provide further specific correlations of strength with local stiffness. Tubes not tested to failure at room temperature will then be subjected to elevated temperature testing and/or soaking, with subsequent room temperature measurements of local stiffnesses and global stiffness and failure at elevated temperatures. Sectioning and testing of tubes failed at elevated temperatures can then be compared to results obtained at room temperature to assess additional degradation modes.

Finally, a new algorithm to deduce ply level properties given measured global strains, applied loads, and laminate orientations has been developed by the MRG, and was used here to calculate ply level properties for the OR2-C1 SiC/SiC tube. The algorithm requires measurements of axial and shear strain during axial and torsional loading. Thus, strain gage rosettes were also applied front and back to acquire data necessary for inverting to find ply level properties. Values for ply level properties determined were E1=E2=31.4 Msi, G12=17.5 Msi, and a Poisson's ratio of 0.11. It is notable that the axial stiffness of OR1-C1 as measured by strain gages was considerably higher than the average or typical axial stiffness of OR2-C1, but that the maximum measured axial stiffness of OR2-C1 is nearly identical to the gage-measured axial stiffness of OR1-C1.

\section{II.2 Investigation of Nicalon/CAS Flat Specimens}

In this subsection, the extensive study of SiC/CAS glass flat specimens is described in detail. The reasons for studying flat specimens are several. First, the limited supply of $\mathrm{SiC} / \mathrm{SiC}$ tube components supplied during Phase II restricted the extent of testing on those materials. Second, high temperature damage modes in multi-axially reinforced specimens having the same Nicalon fiber reinforcements provide a framework for characterizing damage modes and degradation which is applicable to the $\mathrm{SiC} / \mathrm{SiC}$ materials. Third, the fiber/matrix interfacial region and its effect on mechanical response can also be further investigated by conducting tests on a Nicalon/CAS system. Finally, the extensive data obtained can be used to validate, and/or guide the development of, the MRLife simulation code, and the simulation code can then be used on other systems and components for predictions of performance.

\section{2. a. Specimens and Processing}

The material system used in this investigation, Nicalon/CAS-II, was fabricated (and supplied) by Corning Glass Inc. using a hot-pressing technique. The matrix material, $\mathrm{CAS}\left(\mathrm{CaO}, \mathrm{Al}_{2} \mathrm{O}_{3}-2 \mathrm{SiO}_{2}\right)$, is a family of refractory alkaline earth aluminosilicate glass-ceramics developed in the pseudo-binary system of triclinic anorthite $\left(\mathrm{CaO}-\mathrm{Al}_{2} \mathrm{O}_{3}\right.$ - 
$\left.2 \mathrm{SiO}_{2}\right)$ and mullite $\left(3 \mathrm{Al}_{2} \mathrm{O}_{3}-2 \mathrm{SiO}_{2}\right)$. Its attributes as a matrix material for ceramic fiber reinforcements are many: e.g., nominally fully crystalline ceramic of nearly full density with low specific weight; a high degree of thermal stability for an extended time at $1300^{\circ} \mathrm{C}$; inherently oxidation resistant; tailorable elastic and thermal properties through chemical doping; low elastic modulus for good load transfer and reduced thermal stresses; and amenable to various low cost processing routes offering the potential for near shape component fabrication. Nicalon ceramic fibers were used for the reinforcement. The fiber is composed of ultrafine crystalline beta-SiC with excess carbon and 9 to 11 percent oxygen $\left(\right.$ as $\mathrm{SiO}_{2}$ ).

Three different laminates $[0]_{8},[0 / 90]_{28}$, and $[0 / 90]_{48}$, manufactured by Corning Glass Inc. were used in this investigation. The $[0]_{8}$ and $[0 / 90]_{25}$ laminates were purchased, and provided by Rolls-Royce Inc. The third type of laminate $[0 / 90]_{48}$ was purchased and provided by the Materials Response Group. $[0]_{8}$ and $[0 / 90]_{23}$ specimens were used primarily for flexure and monotonic tension tests to observe some of the basic damage modes under flexure loading and to characterize heat treatment effects on the tensile strength. $[0 / 90]_{48}$ specimens were used primarily for damage characterization of asreceived and heat treated specimens under monotonic and cyclic tension loading.

After nondestructive evaluation, using ultrasonic c-scanning and acoustic microscopy, the panels were marked and prepared for machining. Specimens were labeled according to their panel identification and location within the panel. All specimens were oriented with the $0^{\circ}$ fiber direction parallel to the cutting axis (longitudinal direction), supported on plexiglass using double sided tape or wax, and water cooled when they were cut. Two different sizes of specimens were cut from panels provided by Rolls-Royce Inc. and the Materials Response Group, respectively. After the specimens were cut, they were polished on both longitudinal edges with 320,400 , and 600 grit SiC papers and were then polished using 5, 1, 0.3 micron alpha alumina powder mixed with water on a TEXMET polishing cloth. The specimens ( 3 for each test) were separated into four groups after polishing and sent to Rolls-Royce Inc. for heat treatments. Three groups were heat treated for 100 hours at three different temperatures $\left(900^{\circ}, 1000^{\circ}\right.$, and $\left.1100^{\circ} \mathrm{C}\right)$ in air and were returned to the Materials Response Group for mechanical characterizations. End tabs of glass filled epoxy were bonded to the ends of the specimens for tension and fatigue tests to facilitate gripping and to prevent shredding during tests.

\section{II.2.b. Experimental Procedures}

Tension-tension fatigue tests were conducted at room temperature on the four groups of heat treated and as-received $[0 / 90]_{4 s}$ specimens. In order to determine the effects of heat treatments on mechanical performance and the influence of load levels on damage development, load levels were selected as percentages of tensile strength of $[0 / 90]_{2}$ specimens, given in Table I. The selected load levels were $65 \%$ and $85 \%$ of the mean tensile strength of each group. 
Fatigue tests were run in load control at $10 \mathrm{~Hz}$ and $\mathrm{R}=0.1\left(\mathrm{~s}_{\min } / \mathrm{s}_{\max }\right)$ on an MTS $880,20 \mathrm{kip}$ system. Loading was halted periodically in order to measure stiffness change and damage development. The procedure employed during this inspection is: halt cyclic loading, return load to zero, load to mean load to measure the load and strain, perform NDT (surface replication), and resume cycling loading. This procedure results in a documentation of damage development and the corresponding changes in Nicalon/CAS glass-ceramic matrix composites as a function of fatigue cycles. Such results are frequently used for polymeric matrix composite laminates to estimate the cycles remaining until specimen failure. Specimens that survived $10^{6}$ cycles without fracture were tensile tested to failure.

\section{TABLE I}

Mean tensile strength of $[0 / 90]_{2 s}$ Nicalon/CAS-II laminates [5].

\begin{tabular}{cc} 
Condition & Tensile Strength $(\mathrm{ksi})$ \\
\hline as-received & 25.1 \\
$900^{\circ} \mathrm{C}$ & 22.8 \\
$1000^{\circ} \mathrm{C}$ & 26.0 \\
$1100^{\circ} \mathrm{C}$ & 23.2
\end{tabular}

\section{II.2.c. Results}

An overall longitudinal stiffness reduction curve for an as-received specimen tested at the $65 \% \mathrm{~S}_{\text {ult }}$ cycle load level is shown in Fig. 13. This curve displays a rapid reduction of $40 \%$ of its original longitudinal stiffness in the first 100 cycles. From 100 cycles to 1000 cycles the reduction rate of longitudinal stiffness decreased and the curve started to level off after $1 \mathrm{~K}$ cycles. Another decrease of longitudinal stiffness was observed just before final failure.

Figure 14 shows the increase of transverse matrix cracking (the primary damage mode) as a function of fatigue cycles. Again, after the initial rapid change of the crack spacing, the rate of increase in crack spacing due to fatigue loading decreased. Longitudinal cracks (or splitting) and delaminations were not observed during the initial stage.

In addition to the change of longitudinal stiffness measured during fatigue tests, there was a change of temperature measured on the surface of the specimens under fatigue loading. A temperature profile obtained from the surface, in the gage section, is shown in Fig. 15, for a specimen tested at $65 \% \mathrm{~S}_{\text {ult }}$. It is seen that there is a rapid increase of surface temperature followed by a plateau during the intermediate stage of fatigue life. As shown in Fig. 15, a rapid increase of surface temperature was also measured before final failure. Although the temperature profile may be affected by some local effects, we found that it can be qualitatively used as an indication of damage activities during fatigue loading. 


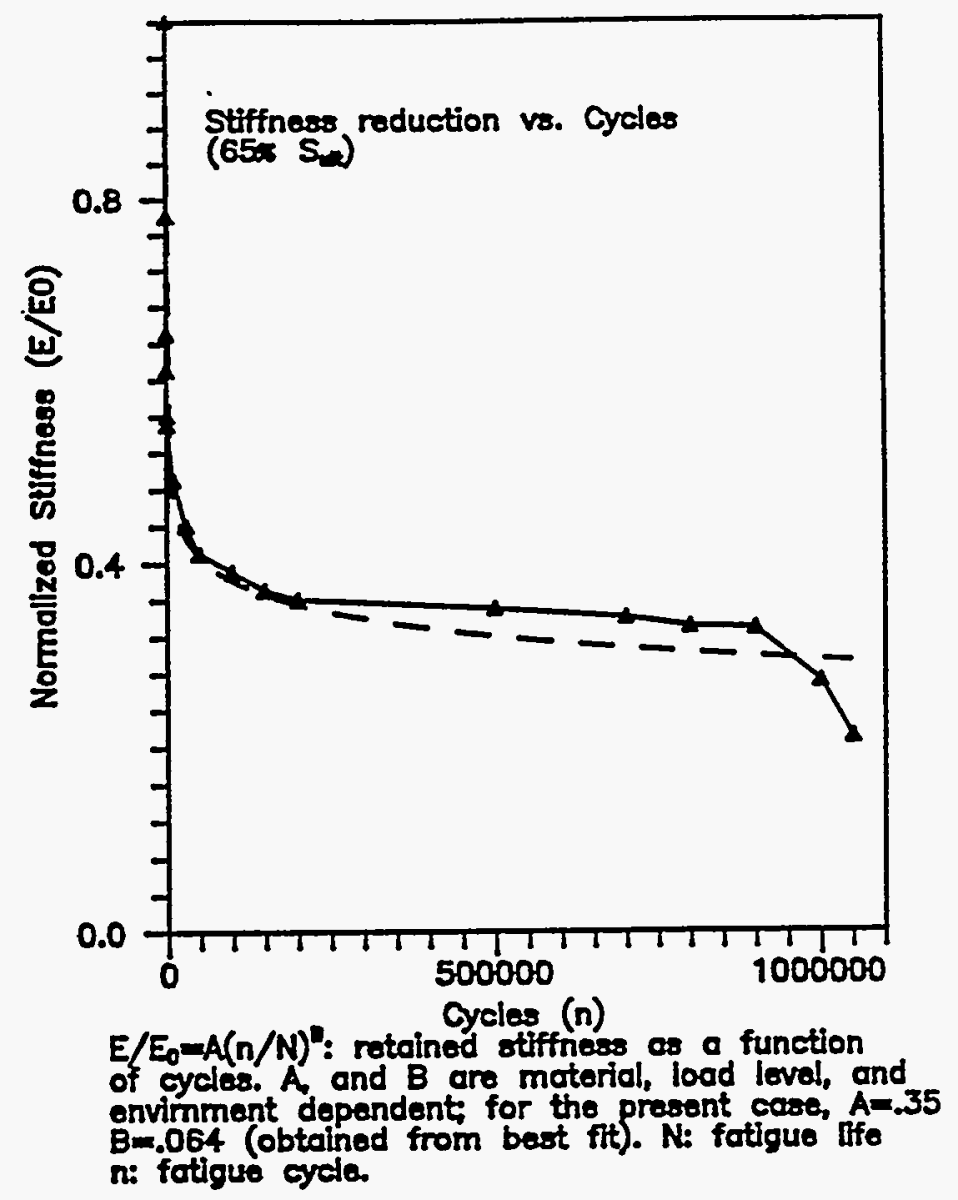

Figure 13. Stiffness reduction versus cycles at $65 \%$ of ultimate strength. Dashed line is a best fit to the form $E / E_{0}=A(n / N)^{B}$ where $n$ is the cycle number and $N$ the life.

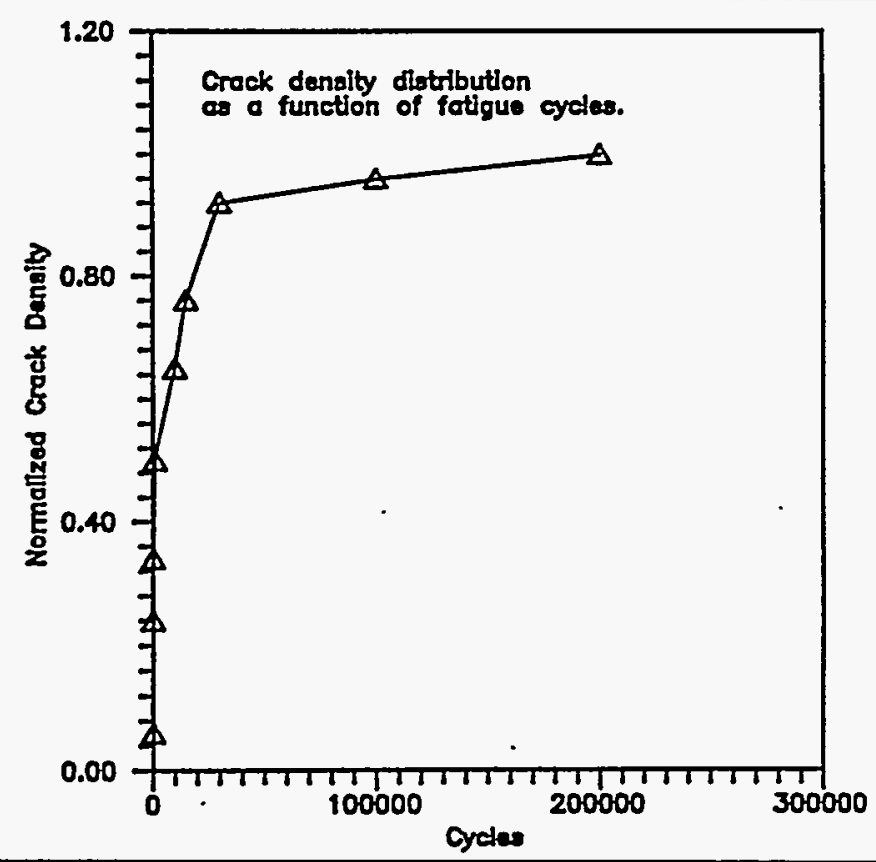

Figure 14. Transverse crack density versus fatigue cycles 


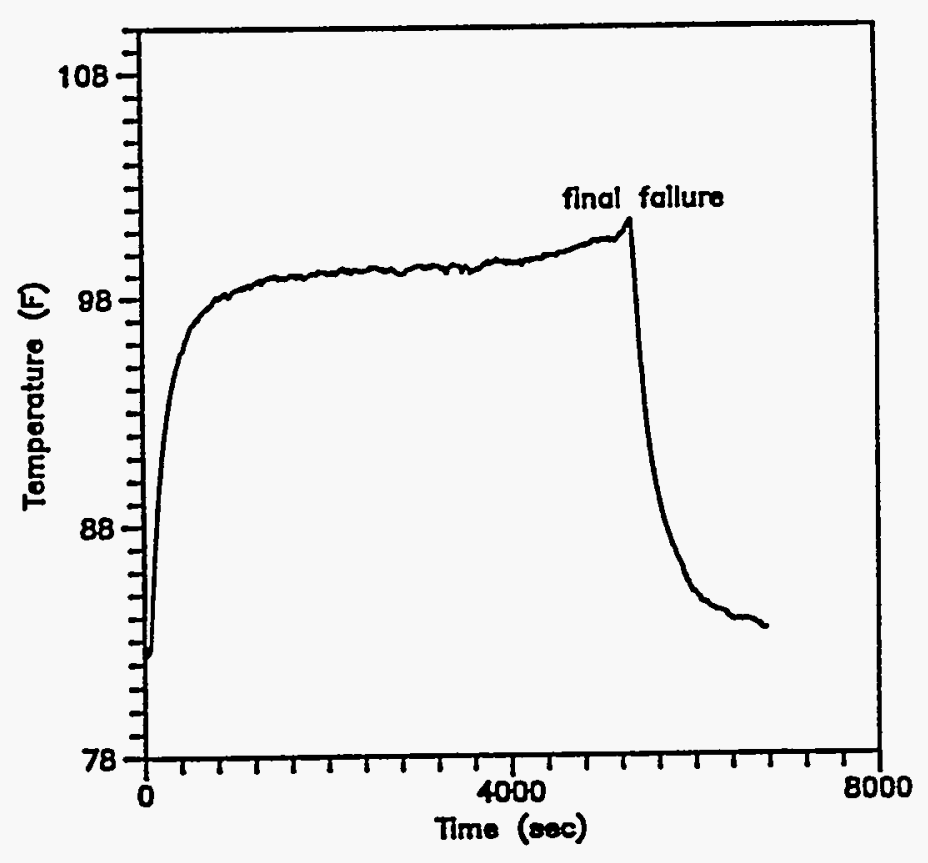

Figure 15. Surface temperature versus time (sec) during $10 \mathrm{~Hz}$ cycling.

The measured average reduction of longitudinal stiffness during the first $1 \mathrm{~K}$ cycles in a $65 \% \mathrm{~S}_{\text {ult }}$ loaded specimen was as much as $46 \%$ of its original longitudinal stiffness. It was expected that the dominant contribution to the modulus degradation in the first 1000 cycles was due to the transverse matrix cracking. In order to further investigate the reduction of stiffness due to transverse cracks, a discount scheme can be utilized. Material properties used in this analysis are provided by the materials manufacturer, Corning Glass Inc. The longitudinal stiffness of an undamaged $[0 / 90]_{4 \mathrm{~s}}$ laminate is calculated to be $17.5 \mathrm{Msi}(121 \mathrm{GPa})$ based on the following lamina properties of Nicalon/CAS-II material:

$$
\begin{gathered}
\mathrm{E}_{1}=18 \mathrm{Msi}(124 \mathrm{GPa}), \mathrm{E}_{2}=17 \mathrm{Msi}(117 \mathrm{GPa}) \\
v_{12}=0.26 \mathrm{G}_{12}=7 \mathrm{Msi}(48 \mathrm{GPa})
\end{gathered}
$$

In the case of saturation of transverse cracking, it can be assumed that the transverse stiffness, $E_{22}$, and the shear modulus, $G_{12}$ of the $90^{\circ}$ plies are reduced to zero. If these discounted properties are utilized in a laminate plate analysis, the predicted laminate stiffness becomes $9.3 \mathrm{Msi}(64 \mathrm{GPa})$. Thus, the laminate longitudinal stiffness reduction due only to saturation of transverse cracks in $90^{\circ}$ plies is $47 \%$, which is very close to the average reduction of stiffness measured after $1 \mathrm{~K}$ cycles. 
Stiffness reduction in the intermediate stage was relatively small, about $15 \%$. The increase in transverse cracks is small in number and in size during the intermediate stage. The transverse matrix cracks extended into the material depth direction in both the $0^{\circ}$ plies as well as $90^{\circ}$ plies during the intermediate stage. A further investigation of longitudinal cracks and delaminations was carried out at several intervals during the intermediate stage by X-ray radiography, and the results indicated that no longitudinal cracks and delaminations were observed.

The rapid temperature rise to an approximately steady-state surface temperature after about 1000 cycles, is consistent with the concept of relative fiber/matrix interfacial sliding during fatigue loading, with the concomitant generation of heat due to friction. Similar behavior to that observed here as been found in uniaxial samples by other workers. The stability of the temperature after matrix cracking over the intermediate portion of life indicates a stable friction and interfacial sliding resistance.

Following on the calculation of discounted axial stiffnesses, the calculated lamina stresses in the $0^{\circ}$ plies in the fiber direction, $\sigma_{11}$, and transverse to the fibers, $\sigma_{22}$, based on the same assumption as above, increased about 2 times, and 33 times their original values respectively. If we compare the increase of transverse lamina tensile stress in the $0^{\circ}$ plies with the transverse lamina tensile stress, $\sigma_{22}$ in the $90^{\circ}$ plies that causes fiber debonding and matrix cracking, it is found that the transverse lamina tensile stress in the $0^{\circ}$ plies is about 3 times higher than that critical value in the $90^{\circ}$ plies. Thus, transverse tension in the $0^{\circ}$ plies is sufficient to cause fiber debonding and matrix cracking (or "splitting") in the $0^{\circ}$ plies. Using the same stiffness discount method described earlier, however, only a 3\% laminate stiffness change is predicted for this damage mode. Although not reflected in a large change in laminate stiffness, longitudinal cracking may have some effect on the interfacial sliding of the fibers, and thus play a role in the longterm fatigue properties of the material. In particular the final failure may be associated with the observed longitudinal splitting, a correspondingly modified interfacial sliding, which is manifest in both an observed increased surface temperature and decreased modulus.

An important damage feature was noticed on the surface of pulled-out fibers in fatigue-tested specimens. It is shown in Fig. 16 that the fiber surface was severely damaged during the fatigue test due to wear. This type of damage was not observed in the static tensile loaded specimens. Thus, this appears to be a characteristic damage mode in ceramic matrix composites due to cyclic loading under these conditions. It is believed that this wear effect may be due to the low interfacial bonding strength which allows rubbing between debonded fibers and the matrix under cyclic loading, and which also leads to the heat generation as noted above. Figure 16 suggests that such surface damage caused by wearing action was directly related to fiber fracture, i.e., it appears that the fiber surface damage may facilitate fiber fracture. This is believed to be the first report of this phenomenon. The damage shown in Fig. 16 also suggests that the carbon coating on the Nicalon fibers has fragmented during the cyclic loading at room temperature. This fragmentation process may create local stress concentrations 


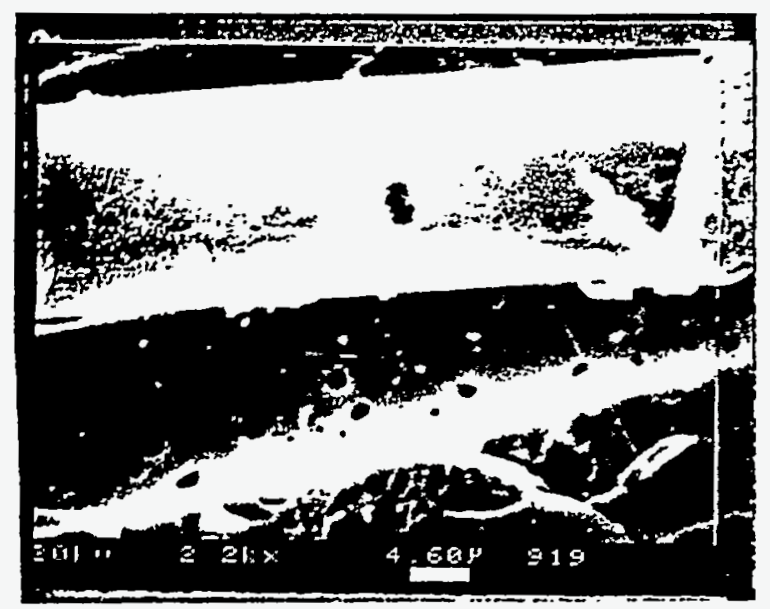

a

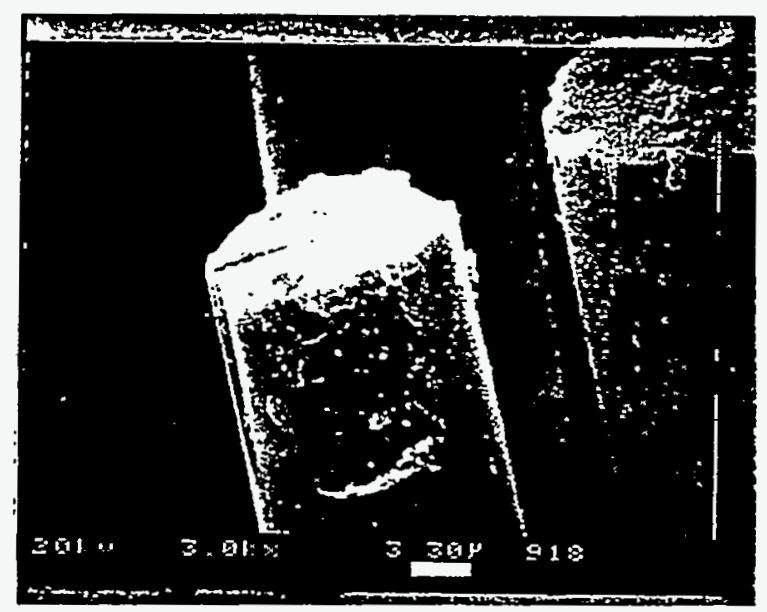

b

Figure 16. Fiber surface damage (a) caused by fatigue cycling, (b) at fiber fracture sites

associated with the local complexity of the geometry introduced by the fragmentation process, and it may also create small "pits" or "scars" in the fiber during that process.

If wear debris simultaneously increases the fiber sliding and degrades the fiber strength, then the final stage behavior can be rationalized as follows. Increased frictional sliding leads to increased heat and temperature, while the fiber damage lowers the specimen stiffness at the same time. In principle, the relationship between modulus, temperature, extent of fiber damage, and sliding resistance, can be derived and should provide a unified picture of the final stage of fatigue life. These relationships are the subject of our on-going and future performance simulation work. Since this work was completed, similar general features have been observed in some uniaxial and woven $\mathrm{SiC} / \mathrm{SiC}$ flat specimens and hence the generic damage modes identified here are expected to be very important in $\mathrm{SiC} / \mathrm{SiC}$ tube components.

The coating fragmentation damage mode is, however, greatly influenced by exposure of the material to elevated temperature. Some of our specimens were subjected to 100 hours of exposure to 900,1000 , or $1100^{\circ} \mathrm{C}$ air. For the last two cases, this exposure was found to reduce or eliminate the carbon fiber coating, and deposit a silicon oxide region in the fiber-matrix interlayer region. This oxide interferes with the fiber-matrix "decoupling" or "sliding" achieved by the carbon coating. In those cases, the fiber damage shown in Fig. 16 was not observed, but corresponding reductions in static strength and life of the materials accompanied that situation due to a lack of sliding. Hence, it appears that the fiber-matrix interlayer fragmentation damage mode, thought to be identified here for the first time, is greatly affected by exposure to elevated temperature, and may become inactive if a "rigid" interlayer such as an oxide forms in that region, but replaced by a more dangerous brittle failure mode. The importance of the fiber/matrix debonding and ensuing fiber sliding is thus demonstrated, and the degradation caused by such sliding is a key contributor to long-term composite fatigue failure. 


\section{II.3 Performance Simulation - The MRLife Code}

Over the last 12 years, the Materials Response Group has developed a performance simulation code that combines models of ply-level behavior to predict remaining strength and life of composite laminates.[9-11] The objective of the simulation code is to deal with the evolution of properties and performance, i.e., to bring our models of processes and behavior to a collective consequence, usually to predict durability, damage tolerance, safety of composite components. The present program focuses on the relationship of this modeling to the laboratory characterization of ceramic composite tubes. Figure 17 describes the scope of this work.

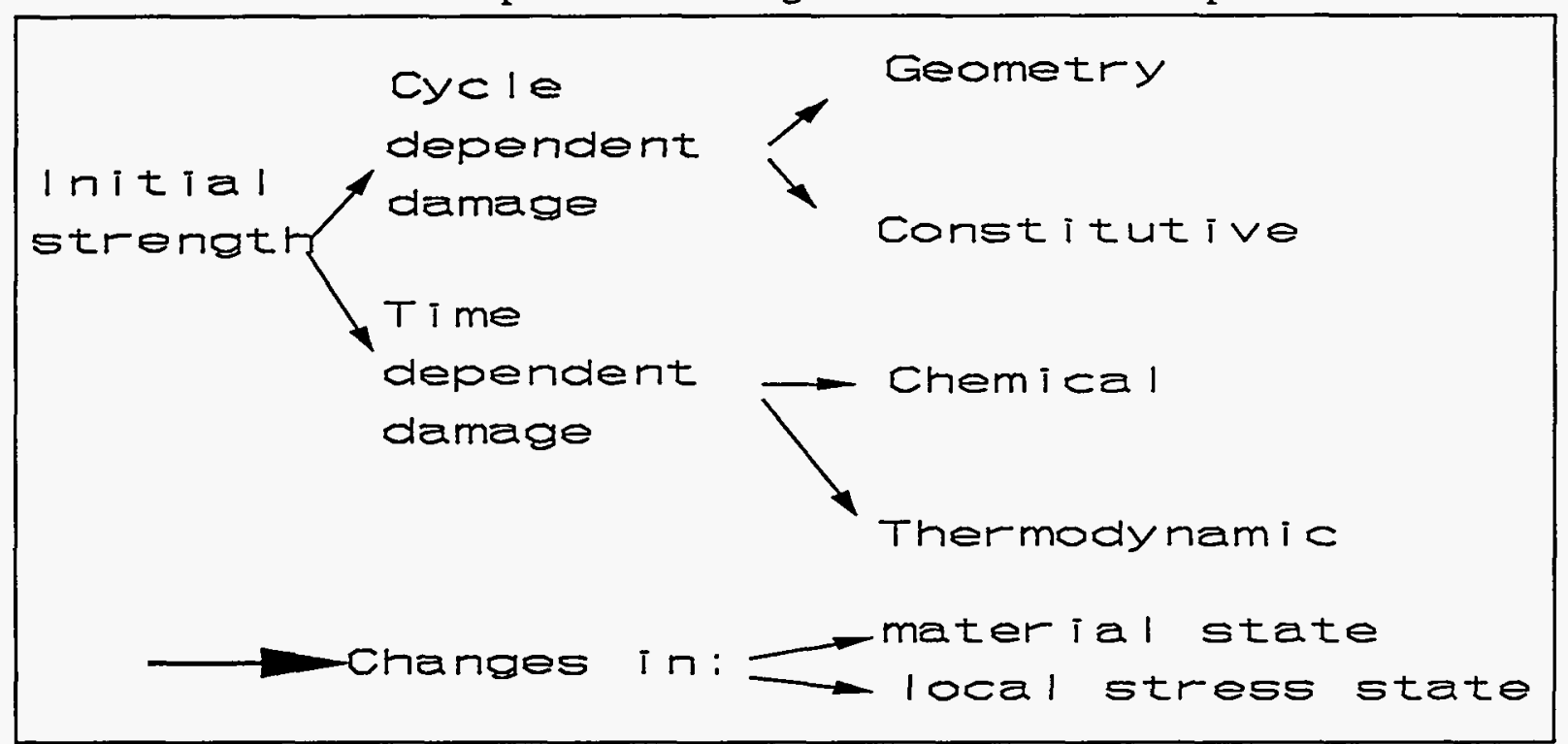

Figure 17 Damage processes in composite material systems.

As Fig. 17 suggests, this evolution may consist of mechanical events such as defect formation, or chemical events such as oxidation or environmental attack, or thermodynamic events such as diffusion or morphology variations that reduce the capability of the material system to sustain mechanical loading. Of course, we could begin with a "degradation criterion" other than strength, and only the details of the subsequent argument would change. The conceptual substance would be quite similar.

This evolution is represented by a "strength evolution integral," of the form in equation

$$
F_{x}=1-\int_{0}^{1}\left(1-F_{2}\right) 1(n / N)^{(1-1)} d(n / N)
$$

In this equation, $F_{I}$ is the normalized remaining strength (which has unit value initially, and degrades to 0 ), $\mathrm{n}$ is the number of cycles of loading (but could be replaced with time or generalized time parameters such as entropy), $i$ is a parameter which is usually constant for a 
given material system, and $F_{a}$ is the normalized value of the local applied stress. $F_{a}$ can be a failure function based on the Tsai-Hill or other criterion. $\mathrm{N}$ in equation 1 is the "life" under current conditions, i.e., under current states of stress and states of material. $\mathrm{N}$ could be the fatigue life under constant conditions, or it could be the life associated with a kinetic degradation such as diffusion, oxidation, or even viscoelasticity.[12]

This equation is evaluated in the critical element defined by the controlling failure mode, as we have described earlier. Our problem, then, becomes the description of

$$
F_{a}=F_{a}\left(\frac{\sigma_{i j}(n)}{X_{i j}(n)}\right) ; N=N(n) ; E_{i j}=E_{i j}(n)
$$

which are the local normalized level of applied loading, the life (determined by the rate equation for the controlling degradation process) of the local element in the representative volume (at the ply level or at the constituent level, according to how our mechanics problem is set), and the inherent stiffness of the material (also defined at the appropriate level). All of these quantities are dependent on evolution, of the general type defined in Fig. 17. In order to correctly represent the degradation of the quantities in equation 2 and in equation 1, we must have considerable information about the rate of the processes that are altering the material or material system.

The Materials Response Group has developed a performance simulation model and code series called MRLife which uses these representations to predict the remaining strength of composites under combinations of cyclic and sustained loading, including such effects as viscoelastic creep, chemical attack, creep rupture, and fatigue loading. The code is based on interpretations of the quantities in equation (1), and shows considerable promise in the representation of combined fatigue - creep behavior.[13-16]

This is a true predictive capability, and can be used, not only to anticipate the performance of composites which have not actually been tested under conditions which have not been applied to such materials in the laboratory, but the simulation can also be used to "design" composite material systems by determining the sensitivity of performance to the details of the constituents and their arrangements.

Fig. 18 shows an example of such a prediction. The figure shows the results of the calculation of the normalized failure function, $F_{a}$, for a loading that is (initially) about 50 percent of the strength of the laminate in tension $(R=0.1)$. The laminate is symmetric with a stacking sequence of $[0,45,0,-45,0] \mathrm{s}$. The material is hypothetical, for demonstration purposes. In the simulation shown, a representative volume of one ply thickness of the 0 degree ply is used for the analysis, and for this demonstration, only the fiber strength is degraded (as it might be by oxidation or chemical attack) to a very small value over one million cycles. The failure function increases by about 26 percent over the life of the specimen, which is reduced from 1.5 million to about 210 thousand cycles - about 14 percent of the baseline life. Also, the basic nature of the damage tolerance is altered by the fiber degradation; the remaining strength curve is relatively unchanged at the beginning of life, and drops off sharply near the end. For this example, the fiber degradation was taken to be linear with time (since gas diffusion controlled weight loss would be linear with time), but the remaining strength is quite nonlinear. This is a good example 




$\rightarrow-$ Remaining strength $\rightarrow-$ Failure function

Figure 18 Simulation of the remaining strength of a graphite epoxy specimen subjected to tensile fatigue.

of the type of information that can be gotten from a mechanistic simulation based on mechanics (at the ply level in this case). Numerous other simulations have been discussed in the literature for high temperature aerospace structural material systems.[13-16]

We are learning to represent laboratory behavior in these models. An example is the modeling of the effects of creep-rupture mechanisms. We have determined that damage mechanisms that cause eventual failure can be represented by changes in the ply-level (unidirectional) strengths that are entered into the laminate analysis used in the model. For example, for $\mathrm{SiC}$ reinforced CAS (for which we were able to find specific creep-rupture data), we have decided to alter the fiber-direction ply tensile and compression strength according to

$$
X(\hat{t}) / X_{0}=1+\left[A \hat{t}+B \hat{t}^{2}+\ldots\right] D \frac{T-E}{F-T}
$$

in which $\hat{E}$ is the log of time in hours, A-F are material constants, $X(\hat{t})$ is the strength at time $\hat{E}$, and $\mathrm{T}$ is temperature in absolute. Notice that this has the effect of reducing strength, "instantaneously," as a function of temperature, and of scaling the subsequent reduction with time (accelerating it with temperature, for example). A plot of the manner in which the temperature scaling varies for that material system appears in Fig. 19.

\section{High Temperature Composites}

The Materials Response Group is heavily involved in the study of a number of ceramic composite systems, including $\mathrm{SiC} / \mathrm{SiC}$ (CVD) systems, oxide/oxide systems, and Lanxide 




Figure 19 Scale factor in equation 3 as a function of absolute temperature.

materials, with various fiber architectures. Some of the capabilities of the Materials Response Group are unique in this area. Recently, for example, the MRG worked with the MTS Corporation to design a servohydraulic test system that can superpose (independently) small (up to 2000 lbs.) excitations at high frequencies (up to about $1500 \mathrm{~Hz}$.) on low frequency (up to about $10 \mathrm{~Hz}$.) larger amplitude excitations (up to about 10,000 lb. tension/compression, 7,000 in.lb. torsion). This system has grips that accept 1.5 in. tubes, and operates up to temperatures of about 3,200 degrees F. This system makes it possible, for the first time, to test superposed vibrational loading such as the explosive loading of a combustor bucket superposed on the structural vibrations of that device. It also makes it possible to study a variety of frictional and acoustic fatigue applications, rate effects, and high temperature stability of these materials.

The present philosophy has been applied to several ceramic composite systems, including $\mathrm{SiC} / \mathrm{SiC}$, Aluminum based oxide/oxide systems, Nicalon / CAS, Nicalon / LAS, and numerous carbon reinforced polymer systems.[17-18] Only a few representative results will be presented here. A comprehensive description of the details of the simulations, especially the manner in which the rate equations for creep, creep rupture, oxidation, and matrix cracking were obtained, is beyond the scope of this paper, but is of critical importance to the success of the effort. Some of those details are not yet published, but will appear shortly. To that extent, these results should be viewed as illustrative and preliminary.

Figure 20 shows an example of the fatigue performance of a cross ply Nicalon / CAS laminate at about $1000^{\circ} \mathrm{C}$. The degradation of the laminate is a strong combination of microdamage due to the cyclic mechanical loading, and oxidative degradation of the carbon coating on the fibers and the fibers themselves. The degradation of the fundamental strength of the material reduces the denominators of the failure criterion used, and the relaxation of stress in the matrix by matrix cracking increases the stress in the fibers and, thereby, increases the 


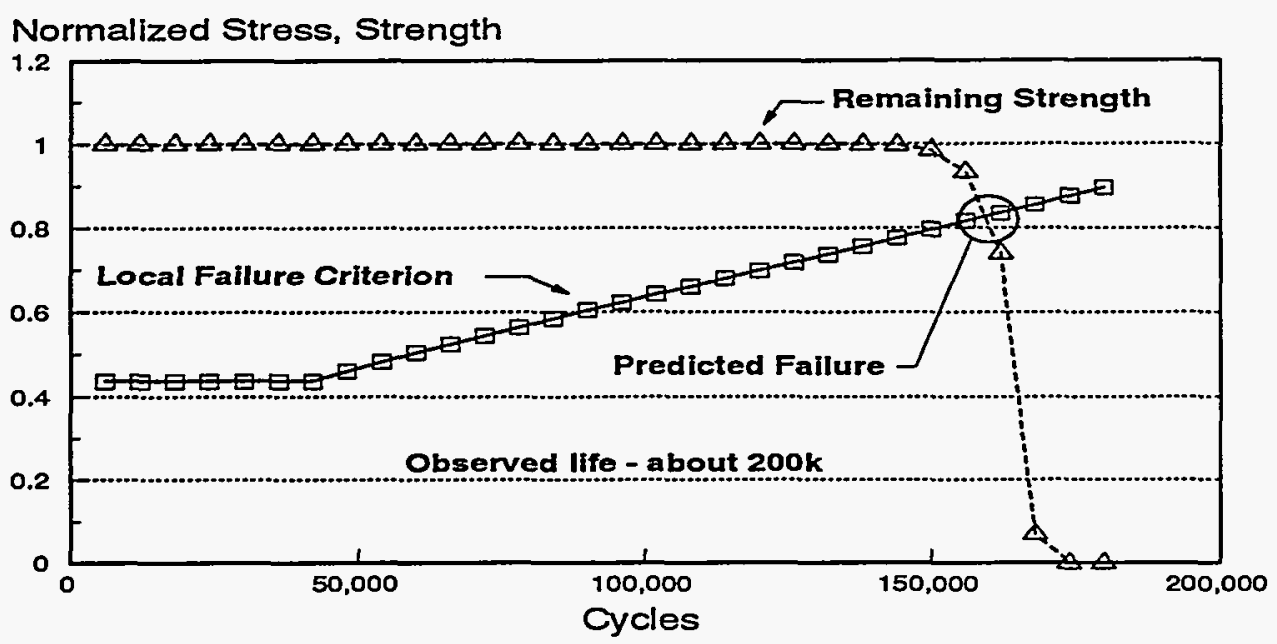

Figure 20 Predicted remaining strength and predicted and observed life for a Ni/CAS laminate at $1000^{\circ} \mathrm{C}$.

numerator of the failure function. The net result is a steady rise of the local failure criterion throughout the test, and an acceleration of the failure event (compared to the room temperature result, for example, which has a life of over one million cycles at this load level). When the accumulation of damage reaches a certain point, the remaining strength decreases quickly, and the specimen fails, at a predicted life which is quite similar to the observed value of about $200 \mathrm{k}$ cycles. This "sudden death" type of failure is quite common in these materials under these conditions.
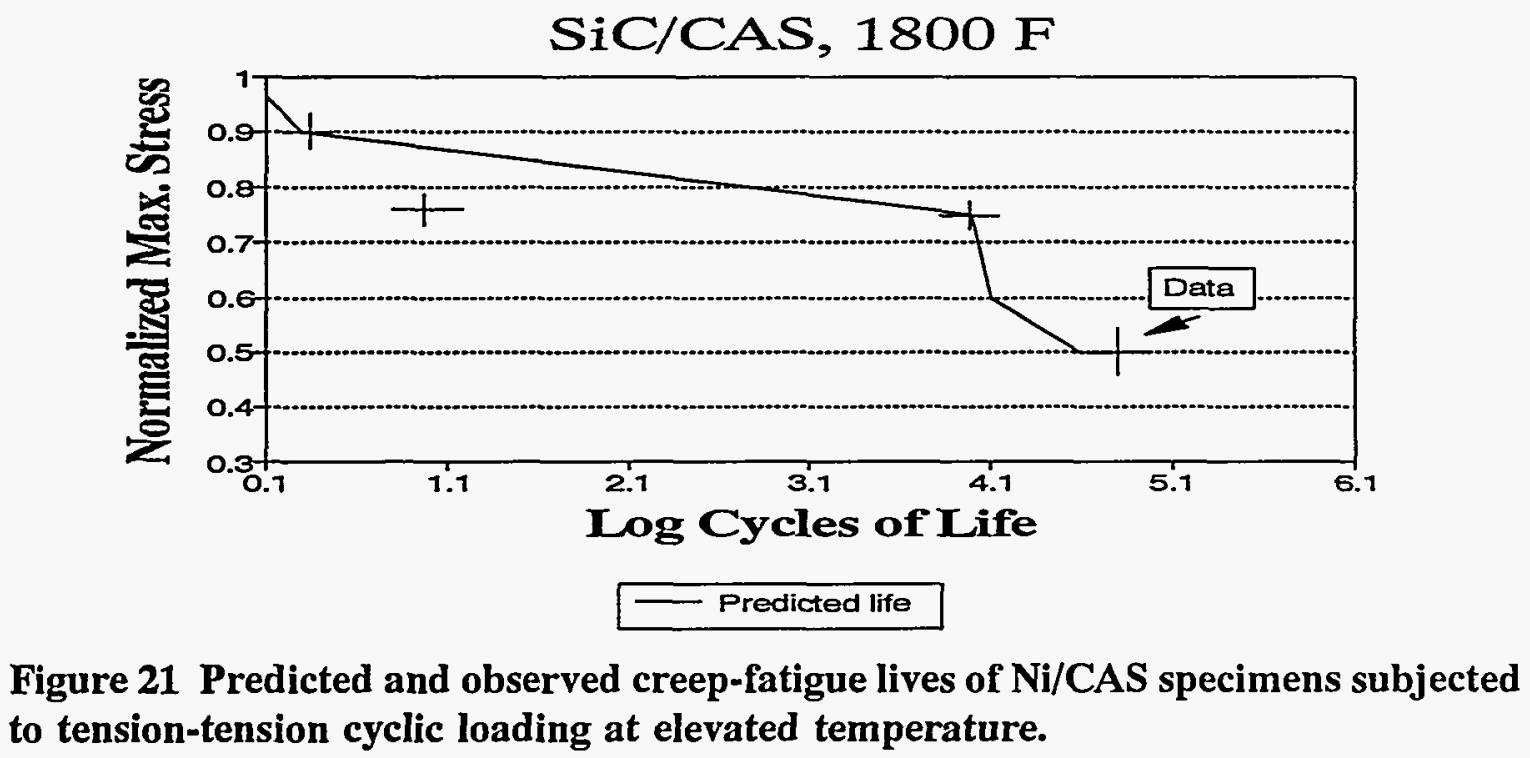

Figure 21 shows predicted and observed life for several loading levels at $1000{ }^{\circ} \mathrm{C}$. It is seen that at low stress levels, time-dependent oxidation is predicted (and observed) to control the life of the material, while at high cyclic load levels the degradation due to mechanical loading is dominant. This type of combined (interactive) effect cannot be gotten from linear models nor 
from phenomenological curve fits. Mechanistic models based on the constituent-level behavior and physics, such as the present one, are necessary for this task.

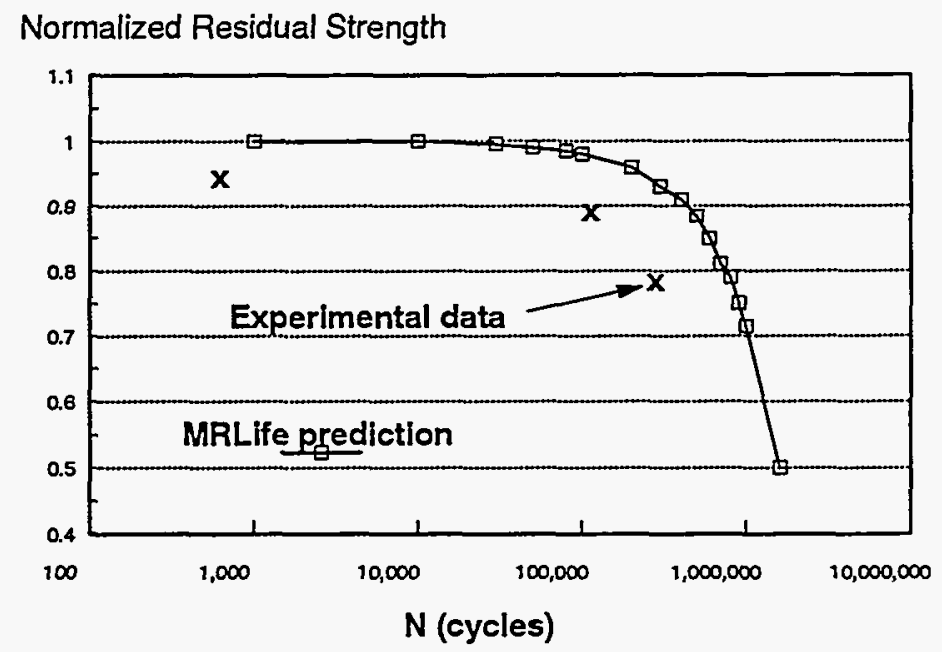

Figure 22 Remaining strength predictions and observations for a Quasi-isotropic center notched coupon fatigue loaded with $R=-1$.

Numerous predictions for polymer composite have also been successfully made. Figure 22 shows an example of predictions of remaining strength as a function of cycles for a fully reversed loading of an AS-4/PEEK(APC-2) center-notched coupon, compared to experimental data. The predictions were made based on data for unidirectional fatigue of that material under tensile loading, only. Rate equations for matrix cracking were estimated on the basis of past experience. The predictions were made with MRLife 8 for this complex laminate, geometry, and loading. The agreement is seen to be within about 10 percent, which is typical of our experience for the prediction of remaining strength.

Our modeling efforts to date suggest that the durability and damage tolerance of composite systems can be modeled in terms of micromechanical representations of strength which make it possible to represent changes in global composite properties and performance in terms of local changes in the constituents, the interfaces and interphases between constituents, and the local geometry (as influenced by defect development). In this way, micromechanical modeling can be used to represent microstructure-property interactions and evolution, as the properties of the constituents and local geometry change. Since these constituent changes or local geometry changes can be measured directly and independently, the approach provides a sound and systematic method of representing, and in some cases predicting, the evolution of strength and life at the global level. Examples of applications of the approach have also been shown, with good success in a performance simulation of the remaining strength and life of composite laminates (even at elevated temperatures) with limited input data. This approach holds the promise of providing the community with a systematic method of relating the details of how composite systems are made to the manner in which they perform under long-term exposure to complex combinations of mechanical, thermal, and other environmental combinations. Although the approach is new in many respects, many applications over the last ten years have provided a sound basis for progress, and a good motivation for continued effort in this direction. 
Continuing work is especially focused on situations in which complex combinations of changes in material state and stress state dominate the remaining strength and life of complex material systems, especially high temperature polymer and ceramic based composites. The present program has made it possible to conduct basic research necessary to develop the mechanistic models of material strength and degradation rates that must be used as inputs to the simulation method we have developed. In turn, the simulation method has provided us with a means to combine the information and understandings we have developed to estimate remaining strength and life, the behavior of primary importance to designers of components and material systems. The present program continues to concentrate on the characterization and understanding of ceramic composite tubes, as a method of moving from laboratory understandings to engineering advances. 


\section{Summary}

Phase II of the Investigation of Properties and Performance of Ceramic Composite Components has accomplished all of the basic objectives stated at the outset of the program, as described in detail in Section II.

Reliable test methods for high temperature, biaxial testing of structural ceramics have been developed, especially for the testing of tubular components. Testing and evaluation using these procedures has already been carried out on tubular components and flat samples at room and elevated temperatures. In Phase II, the elastic properties of tubes at elevated temperatures and the fatigue properties of flat specimens after high temperature exposure were the main focus of testing. The basic capabilities established in Phase II will carry through to our investigations in Phase III and, in particular, are adaptable to our newly-designed testing machine capable of higher loadings on large cross-section tube components. Failure of $\mathrm{SiC} / \mathrm{SiC}$ tubes at room and elevated temperatures will be investigated in more detail, and correlated with Phase II results.

The long-term performance of ceramic composites exposed to high temperatures has also been investigated. In Nicalon/CAS materials, the results have been characterized in terms of regimes in the cyclic fatigue life and characteristic damage modes such as transverse matrix cracking. Increased surface temperature and decreased elastic modulus have been identified as precursors to final failure. These general damage modes are expected to play an important role in high temperature performance, and so provide a framework for our further investigations on $\mathrm{SiC} / \mathrm{SiC}$ tube components.

The performance of $\mathrm{SiC} / \mathrm{SiC}$ tubes at low temperatures has been found to vary dramatically along the length of the component, and to correlate with microstructural features. Evidence of microstructural variations has been reported back to the processing team at ORNL, and continued feedback to the process development effort will be a key part of our future effort. The new results on $\mathrm{SiC} / \mathrm{SiC}$ tubes have prompted additional investigations prior to beginning studies of durability, and have implications for component failure and performance at elevated temperatures and long times.

The MRLife performance simulation code has been adapted to include aspects of damage evolution and constituent property degradation specific to the performance of ceramic composite components. Correlations of predicted performance with experimental data have demonstrated the validity of the modelling effort. The MRLife code is now capable of making predictions of Nicalon fiber reinforced components, and will support the development of engineering designs utilizing these advanced composite materials.

In summary, Phase II of this program has been successful in furthering the goals of the Fossil energy AR \& TD effort in the area of advanced structural ceramics. Improved understanding of material and component performance under typical environments (elevated temperatures) has been developed. In addition, the basic elastic aspects of ceramic components under complex loadings have been determined, characteristics which are absolutely necessary in the design of components. The proposed Phase III program will carry this work even further 
toward the successful processing, design, and application of ceramic components into fossil energy technologies. 


\section{References}

1. W. W. Stinchcomb, K. L. Reifsnider and T. J. Dunyak, "Investigation of Properties and Performance of Ceramic Composite Components," Technical Report ORNL/Sub/87-SA946/02, DOE/Oak Ridge National Laboratory, June 1992.

2. T. J. Dunyak, K. L. Reifsnider and W. W. Stinchcomb, "An Examination of Selected NDE Methods for Ceramic Composite Tubes," Technical Report ORNL/Sub/87-SA946/01, DOE/Oak Ridge National Laboratory, Dec. 1989.

3. D. P. Stinton, T. M. Besmann and R. A. Lowden, "Advanced Ceramics by Chemical Vapor Deposition Techniques," Am. Ceram. Soc. Bull., 67(2), pgs. 350-355.

4. T. M. Besmann, B. W. Sheldon, R. A. Lowden and D. P. Stinton, "Vapor-Phase Fabrication and Properties of Continuous-Filament Ceramic Composites," Science, Vol. 253, pgs. 1104-1109, 1991.

5. A. J. Caputo, R. A. Lowden and H. H. Moeller, Fiber-Reinforced Ceramic Tubular Composites, ORNL Report No. ORNL/TM-10466, Nov. 1988.

6. M. A. Rigdon and W. S. Hong, "Comparison of High-Temperature Tension Testing Results of Ceramic Fibers," Thermal and Mechanical Behavior of Metal Matrix and Ceramic Matrix Composites, ASTM STP 1080, J. M. Kennedy, H. H. Moeller and W. S. Johnson, Eds., ASTM, pgs. 116-123, 1990.

7. P. K. Brindley, Proceedings, Materials Research Society Symposia, Vol. 81, pgs. 419-424, 1987.

8. A. Chulya and J. Gyekenyesi, "Failure Mechanisms of 3-D Woven SiC/SiC Composites Under Tensile and Flexural Loading at Room and Elevated Temperatures," Ceramic Engineering and Science Proc., Vol. 13, No. 7-8, pgs. 420-432, 1992.

9. K. L. Reifsnider and W. W. Stinchcomb, "Cumulative Damage Model for Advanced Composite Materials," Phase II Final Report to Air Force Materials Laboratory, Wright Patterson AFB, October 1983 (see also General Dynamics Report Number FZM-7149, contract no. F33615-81-C-5049, Fort Worth, TX, 1983)

10. K. L. Reifsnider, Editor, Damage in Composite Materials, Philadelphia: ASTM STP 775, American Society for Testing and Materials, 1982. 
11. K. L. Reifsnider, Editor, Fatigue of Composite Materials, London: Elsevier Science Publishers, 1991.

12. R. M. Christensen, "Lifetime Predictions for Polymers and Composites Under Constant Load," Journal of Rheology, 25(5), pgs. 517-528, 1981.

13. K. L. Reifsnider and W. W. Stinchcomb, "A Critical Element Model of the Residual Strength and Life of Fatigue-loaded Composite Coupons," in Composite Materials: Fatigue and Fracture, ASTM STP 907, H.T. Hahn, Ed., Philadelphia: Am. Soc. for Testing \& Materials, pgs. 298-313, 1986.

14. K. L. Reifsnider, "Performance Simulation of Polymer-based Composite Systems," in Durability of Polymer-Based Composite Systems for Structural Applications, A.H. Cardon and G. Verchery, Eds., New York: Elsevier Applied Science, pgs. 3-26, 1991.

15. K. L. Reifsnider, "Use of Mechanistic Life Prediction Methods for the Design of Damage Tolerant Composite Material Systems," in ASTM STP 1157, M.R. Mitchell \& O. Buck Eds., Philadelphia: American Society for Testing and Materials, pgs. 205-223, 1992.

16. K. L. Reifsnider and Z. Gao, "Micromechanical Concepts for the Estimation of Property Evolution and Remaining Life," in Proc. Intl. Conf. on Spacecraft Structures and Mechanical Testing, Noordwijk, the Netherlands, 24-26 April 1991: (ESA SP-321, Oct. 1991) pgs. 653-657, 1991.

17. K. L. Reifsnider, "Evolution Concepts for Microstructure-Property Interactions in Composite Systems," in Proc. IUUTAM Conference Microstructure-Property Interactions in Composite Materials, Aug. 23-25, 1994, Aalborg, Denmark. (in press).

18. K. L. Reifsnider, "Durability and Damage Tolerance Models for Ceramic Matrix Composites," in Proc. Intl. Conf. on Brittle Matrix Composites, Polish Academy of Sciences, Warsaw, Poland, 12-17 September, 1994. (in press) 


\section{Students supported under contract}

Shin Steven Lee, PhD. May, 1993, now at the Air Force Materials Laboratory.

Lynda L.S. Oleksuk, PhD July, 1995 (expected).

\section{Papers published under contract support}

1. T.J. Dunyak, W.W. Stinchcomb, and K.L. Reifsnider, "Examination of Selected NDE Techniques for Ceramic Composite Components", Damage Detection in Composite Materials, ASTM STP 1128, 1992, pp. 101-120.

2. S.S. Lee, E.G. Henneke, and W.W. Stinchcomb, "On the Flexure Test and Nondestructive Evaluation for Nicalon/CAS Ceramic Composites", Cyclic Deformation and Fracture and Nondestructive Evaluation of Advanced Materials, ASTM 1157, 1992, pp. 312-322

3. S.S. Lee, W.W. Stinchcomb, K.L. Reifsnider, and E.G. Henneke, "Effects of Heat Treatment on Fatigue Behavior of Nicalon/CAS-II Composite Laminates", SEM VIII International Congress on Experimental Mechanics, Las Vegas, NV, June 8-12, 1992.

4. K. Liao, T.J. Dunyak, W.W. Stinchcomb, and K.L. Reivsnider, "Monitoring of Fatigue Damage Development in Ceramic Composite Tubular Specimens by Thermoelastic Techniques", Composite Materials: Fatigue and Fracture, Vol. 4, ASTM STP 1156, 1993, pp. 620-636.

5. W. W. Stinchcomb, "Composite Materials: Fatigue and Fracture", ASTM Special Technical Publication, W. W. Stinchcomb, editor.

6. W.W. Stinchcomb and S.S. Lee, "Damage Mechanisms and Fracture Modes in Nicalon/CAS-II Laminates", Chapter in ASTM Publication (to appear).

7. W.W. Stinchcomb, K.L. Reifsnider, K. Liao, and L. Oleksuk, "Characterization of Ceramic Composite Materials for Gas Turbine Applications", ASME Gas Turbine and Aerospace Congress and Exposition, Cincinnati, OH, May 24-27, 1993, paper \#93-GT-308.

8. W.W. Stinchcomb, K.L. Reifsnider, L. Oleksuk, S.S. Lee, and D.P. Stinton, "Effect of Elevated Temperature and Cyclic Loading on Properties and Damage Modes in Ceramic Composites", Topical Report, Department of Energy, Oak Ridge National Laboratory, May 1993.

9. K.L. Reifsnider, W.W. Stinchcomb, L. Oleksuk, and S.S. Lee, "Effect of Elevated Temperatures and Cyclic Loading on Properties and Damage Modes in Ceramic Composites", Proceedings of the Eight Annual Conference on Fossil Energy Materials, Department of Energy/Oak Ridge National Laboratory, May 10-12, 1994, Oak Ridge TN. 


\section{Distribution List}

A. P. GREEN REFRACTORIES COMPANY

Green Blvd.

Mexico, MO 65265

J. L. Hill

AIR PRODUCTS AND CHEMICALS

P.O. Box 538

Allentown, PA 18105

S. W. Dean

ALLISON GAS TURBINE DIVISION

P.O. Box 420

Indianapolis, IN 46206-0420

P. Khandelwal (Speed Code W-5)

R. A. Wenglarz (Speed Code W-16)

AMA RESEARCH \& DEVELOPMENT CENTER

5950 McIntyre Street

Golden, CO 80403

T. B. Cox

ARGONNE NATIONAL LABORATORY

9700 S. Cass Avenue

Argonne, IL 60439

W. A. Ellingson

J. P. Singh

ARGONNE NATIONAL LABORATORY-WEST

P.O. Box 2528

Idaho Falls, ID 83403-2528

S. P. Henslee

ARMY MATERIALS TECHNOLOGY LABORATORY

SLCMT-MCC

Watertown, MA 02172-0001

D. R. Messier

AVCO RESEARCH LABORATORY

2385 Revere Beach Parkway

Everett, MA 02149

R. J. Pollina

BABCOCK \& WILCOX

1562 Beeson St.

Alliance, $\mathrm{OH} 44601$

T. I. Johnson

BABCOCK \& WILCOX

Domestic Fossil Operations

20 South Van Buren Avenue

Barberton, $\mathrm{OH} 44023$

M. Gold

BRITISH COAL CORPORATION

Coal Research Establishment

Stoke Orchard, Cheltenham

Glocestershire, England GL52 4RZ

J. Oakey
CANADA CENTER FOR MINERAL \& ENERGY

TECHNOLOGY

568 Booth Street

Ottawa, Ontario

Canada KIA OGl

R. Winston Revic

Mahi Sahoo

DOW CORNING CORPORATION

3901 S. Saginaw Road

Midland, MI 48686-0995

H. Atwell

EC TECHNOLOGIES

3614 Highpoint Drive

San Antonio, TX 78217

D. J. Kenton

ELECTRIC POWER RESEARCH INSTITUTE

P.O. Box 10412

3412 Hillview Avenue

Palo Alto, CA 94303

W. T. Bakker

J. Stringer

EUROPEAN COMMUNITIES JOINT RESEARCH

CENTRE

Petten Establishment

P.O. Box 2

1755 ZG Petten

The Netherlands

M. Van de Voorde

GA TECHNOLOGIES. INC.

P.O. Box 85608

San Diego, CA 92138

T. D. Gulden

GEORGIA INSTITUTE OF TECHNOLOGY

Georgia Tech Research Institute

Atlanta, GA 30332

T. L. Starr

IDAHO NATIONAL ENGINEERING LABORATORY

P. O. Box 1625

Idaho Falls, ID 83415

A. B. Denison

B. H. Rabin

LAVA CRUCIBLE-REFRACTORIES CO.

P.O. Box 278

Zelienople, PA 16063

T. Mulholland

LAWRENCE LIVERMORE LABORATORY

P.O. Box 808, L-325

Livermore, CA 94550

W. A. Steele 
LOS ALAMOS NATIONAL LABORATORY

P.O. Box 1663

Los Alamos, NM 87545

J. D. Katz

NATIONAL INSTITUTE OF STANDARDS AND TECHNOLOGY

U.S. Dept. of Commerce

Bldg. 220, Rm A215

Gaithersburg, MD 20899

S. G. Malghan

NATIONAL MATERIALS ADVISORY BOARD

National Research Council

2101 Constitution Avenue

Washington, DC 20418

K. M. Zwilsky

NEW ENERGY AND INDUSTRIAL TECHNOLOGY DEVELOPMENT

Sunshine $60 \mathrm{Bldg}$.

P.O. Box 1151

1-1 Higashi-Ikebukuro 3-Chrome

Toshima-Ku, Tokyo, 170

Japan

H. Narita

S. Ueda

THE NORTON COMPANY

High Performance Ceramics Division

Goddard Road

Northborough, MA 01532-1545

N. Corbin

OAK RIDGE NATIONAL LABORATORY

P.O. Box 2008

Oak Ridge, TN 37831

T. D. Burchell

P. T. Carlson

N. C. Cole

M. A. Janney

R. R. Judkins

R. A. Lawson (8 copies)

D. P. Stinton

P. T. Thornton

OFFICE OF NAVAL RESEARCH

Code 431, 800 N. Quincy Street

Arlington, VA 22217

S. G. Fishman

RESEARCH TRIANGLE INSTITUTE

P. O. Box 12194

Research Triangle Park, NC 27709

T. W. Sigmon
SANDIA NATIONAL LABORATORIES

Department 6211, MS 0710

Albuquerque, NM 87185

R. J. Buss

G. A. Carlson

SHELL DEVELOPMENT COMPANY

P.O. Box 1380

Houston, TX 77251-1380

L. W. R. Dicks

TENNESSEE VALLEY AUTHORITY

Energy Demonstration \& Technology

MR2N58A

Chattanooga, TN 37402-2801

C. M. Huang

3M COMPANY

Ceramic Materials Department

201-4N-01 3M Center,

St. Paul, MN 55144

M. A. Leitheiser

THE JOHNS HOPKINS UNIVERSITY

Materials Science \& Engineering

Maryland Hall

Baltimore, MD 21218

R. E. Green, Jr.

THE MATERIALS PROPERTIES COUNCIL, INC.

United Engineering Center

345 E. Forty-Seventh Street

New York, NY 10017

M. Prager

THE TORRINGTON COMPANY

Advanced Technology Center

59 Field St.

Torrington, CT 06790

W. J. Chmura

UNION CARBIDE CORPORATION

Linde Division

P.O. Box 44

175 East Park Drive

Tonawanda, NY 14151-0044

Harry Cheung

UNITED TECHNOLOGIES RESEARCH CENTER

MS 24, Silver Lane

East Hartford, CT 06108

K. M. Prewo

UNIVERSITY OF WASHINGTON

Department of Materials Science and

Engineering

101 Wilson, FB-10

Seattle, WA 98195

T. G. Stoebe 
VIRGINIA POLYTECHNIC INSTITUTE \& STATE UNIVERSITY

Department of Materials Engineering

Blackburg, VA 24601

W. A. Curtin

K. L. Reifsnider

WESTERN RESEARCH INSTITUTE

365 N. 9th Street

P.O. Box 3395

University Station

Laramie, WY 82071

V. K. Sethi

WESTINGHOUSE ELECTRIC CORPORATION

Research and Development Center

1310 Beulah Road

Pittsburgh, PA 15235

S. C. Singhal

DOE

IDAHO OPERATIONS OFFICE

P. O. Box 1625

Idaho Falls, ID 83415

R. B. Loop

DOE

DOE OAK RIDGE OPERATIONS

P.O.Box 2001

Oak Ridge, TN 37831

Assistant Manager for

Energy Research and Development

DOE

DOE OAK RIDGE OPERATIONS

P. O. Box 2008

Building 4500N, MS 6269

Oak Ridge, TN 37831

E. E. Hoffman

DOE

OFFICE OF BASIC ENERGY SCIENCES

Materials Sciences Division

ER-131 GTN

Washington, DC 20545

J. B. Darby

DOE

OFFICE OF FOSSIL ENERGY

Washington, DC 20545

J. P. Carr (FE-72) GTN

DOE

OFFICE OF VEHICLE AND ENERGY R\&D

CE-151 Forrestal Building

Washington, DC 20585

R. B. Schulz
DOE

MORGANTOWN ENERGY TECHNOLOGY CENTER

P.O. Box 880

Morgantown, WV 26505

R. A. Bajura

R. C. Bedick

D. C. Cicero

F. W. Crouse, Jr.

N. T. Holcombe

W. J. Huber

M. J. Mayfield

J. E. Notestein

J.S. Wilson

DOE

PITTSBURGH ENERGY TECHNOLOGY CENTER

P.O. Box 10940

Pittsburgh, PA 15236

A. L. Baldwin

G. V. McGurl

R. Santore

T. M. Torkos

DOE

OFFICE OF SCIENTIFIC AND TECHNICAL INFORMATION

P. O. Box 62

Oak Ridge, TN 37831

For distribution by microfiche as shown in DOE/TIC-4500,

Distribution Category:

UC-1 14 (Coal Based Materials and Components) 